\title{
Mechanosensory Mechanisms in Bone
}

\author{
Stephen C. Cowin \\ The New York Center for Biomedical Engineering and the \\ Departments of Biomedical and Mechanical Engineering \\ The School of Engineering of The City College and \\ The Graduate School of The City University of New York \\ New York, NY 10031, U.S.A.
}

\begin{abstract}
The mechanosensory mechanisms in bone include (i) the cell system that is stimulated by external mechanical loading applied to the bone; (ii) the system that transduces that mechanical loading to a communicable signal; and (iii) the systems that transmit that signal to the effector cells for the maintenance of bone homeostasis and for strain adaptation of the bone structure. The effector cells are the osteoblasts and the osteoclasts. These systems and the mechanisms that they employ have not yet been unambiguously identified. The candidate systems are reviewed here. In particular a summary is given of the current theoretical and experimental evidence suggesting that osteocytes are the principal mechanosensory cells of bone, that they are activated by the effects of fluid flowing through the osteocyte canaliculi, and that the electrically coupled three-dimensional network of osteocytes and lining cells is a communications system for the control of bone homeostasis and structural strain adaptation. The similarities of the mechanotransduction system in bone with the mechanotransduction system used by the cells of the hearing system will be described. Both cell systems sense mechanical vibrations in a fluid domain.
\end{abstract}

Key words: mechanosensation, bone, hearing, cell systems

\section{Introduction}

It has long been known that living adult mammalian bone tissue adapts its material properties, and that whole bones adapt their shape, in response to altered mechanical loading $[1,2,3,4,5,6,7,8]$. Progress is being made in understanding the cellular mechanisms that accomplish the absorption and deposition of bone tissue. The physiological mechanism by which the mechanical loading applied to bone is sensed by the tissue, and the mecha- 
nism by which the sensed signal is transmitted to the cells which accomplish the surface deposition, removal and maintenance, have not been identified. The purpose of this contribution is to review some of the background research on these mechanosensory mechanisms and to outline candidates for the mechanosensory system. See $[9,10]$ for earlier reviews of similar literature.

Mechanoreception is the term used to describe the process that transmits the informational content of an extracellular mechanical stimulus to a receptor cell. Mechanotransduction is the term used to describe the process that transforms the mechanical stimulus' content into an intra-cellular signal. The term mechanosensory is employed to mean both mechanoreception and mechanotransduction. Additional processes of inter-cellular transmission of transduced signals are required at tissue, organ and organismal structural levels. The mechanosensing process(es) of a cell enables it to sense the presence of, and to respond to, extrinsic physical loadings. This property is widespread in uni- and multicellular animals $[11,12,13,14,15,16]$, plants $[17,18]$ and bacteria [19]. Tissue sensibility is a property of a connected set of cells and it is accomplished by the intracellular processes of mechanoreception and mechanotransduction.

\section{The Connected Cellular Network (CCN)}

The bone cells that lie on all bony surfaces are osteoblasts, either active or inactive. Inactive osteoblasts are called bone-lining cells; they have the potential of becoming active osteoblasts (Fig.1). The bone cells that are buried in the extracellular bone matrix are the osteocytes. Each osteocyte, enclosed within its mineralized lacuna, has many (perhaps as many as 80) cytoplasmic processes (Fig. 1, Fig. 2). These processes are approximately $15 \mu \mathrm{m}$ long and are arrayed three-dimensionally in a manner that permits them to interconnect with similar processes of up to as many as 12 neighboring cells. These processes lie within mineralized bone matrix channels called canaliculi (Fig. 2, Fig. 3). The small space between the cell process plasma membrane and the canalicular wall is filled with bone fluid and macromolecular complexes of unknown composition. All bone cells except osteoclasts are extensively interconnected by the cell process of the osteocytes forming a connected cellular network (CCN) [20,21,22]. The interconnectivity of the CCN is graphically illustrated by Fig. 4 which is a scanning electron micrograph showing the replicas of lacunae and canaliculi in situ in mandibular 


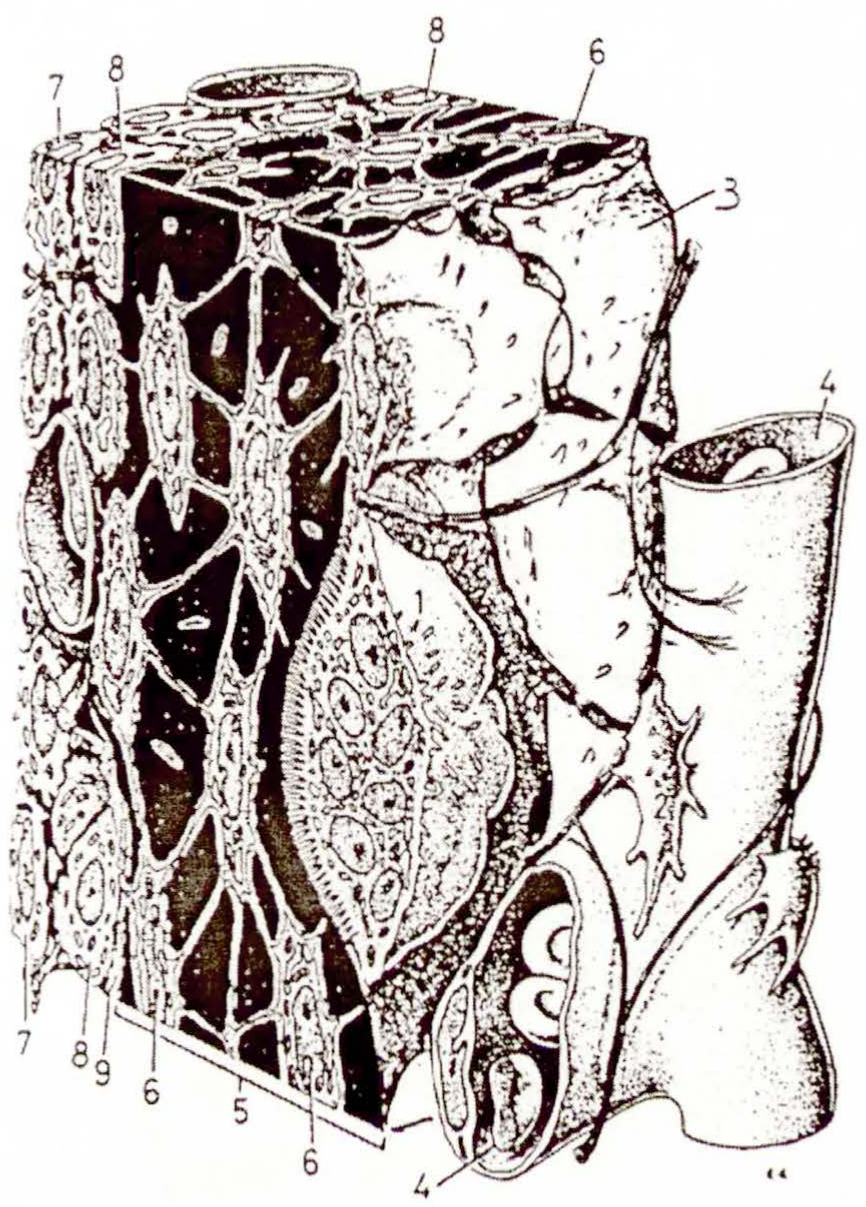

Figure 1. Diagram of a thin bone trabecula (5) showing the four types of bone cells. Osteoblasts (8) and their precursors (7) are shown on the upper surface over a layer of uncalcified osteoid matrix (9), osteocytes (6) are shown in their lacunae, an osteoclast (1) and a bone lining cell (3) are shown on the lower surface. Capillaries (4), containing red blood cells in their lumina, and a fibroblast (2) are shown near the trabecula. Adapted from [194]. 


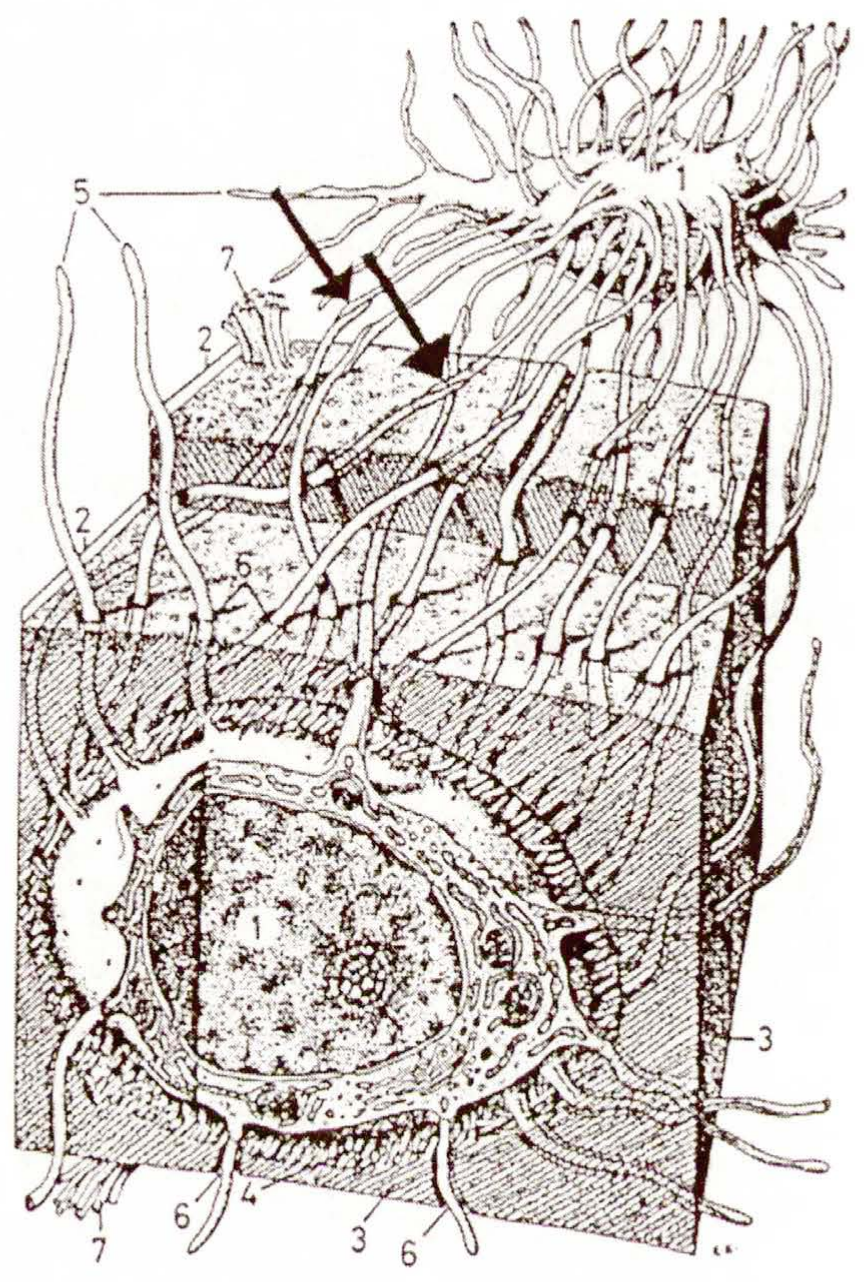

Figure 2. Diagram of two osteocytes (1) in the lamellar bone of calcified bone matrix (3). Two neighboring lamellae (2) with different collagen fiber orientations (7) are visible. The osteocytic cell bodies are located in lacunae and are surrounded by a thin layer of uncalcified matrix (4). Their cell processes (5) are housed in canaliculi (6). Some of the gap junctions between the cell processes are indicated (arrows). Modified from [194]. 


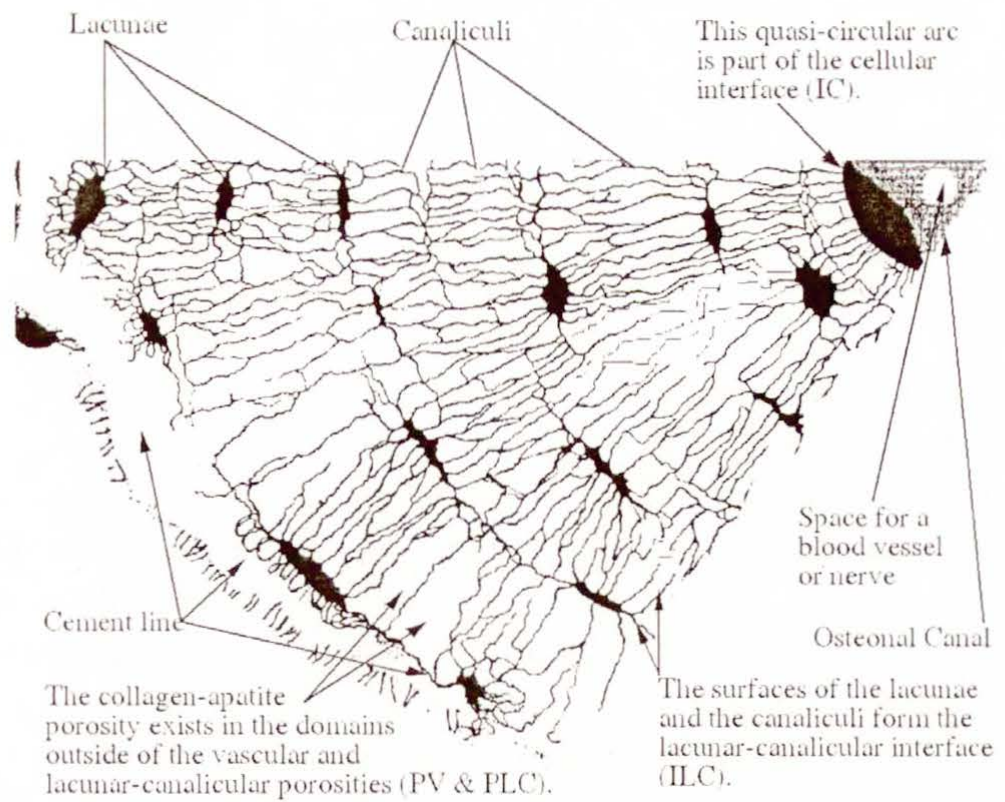

FigurE 3. A pie-shaped section of an osteon. The osteonal canal is on the upper right, the cement line to the left. The osteonal canal is part of the vascular porosity (PV), the lacunae and the canaliculi are part of the lacunar-canalicular porosity (PLC) and the material in the space that is neither PV or PLC contains the collagen-apatite porosity (PCA). The three interfaces, the cement line, the cellular interface (IC) and the lacunar-canalicular interface are each indicated. The radius of an osteon is usually about $100 \mu \mathrm{m}$, and the long axis of a lacuna is about $15 \mu \mathrm{m}$. Using this information it should be possible to establish the approximate scale of the printed version of this illustration. Previously published in [93].
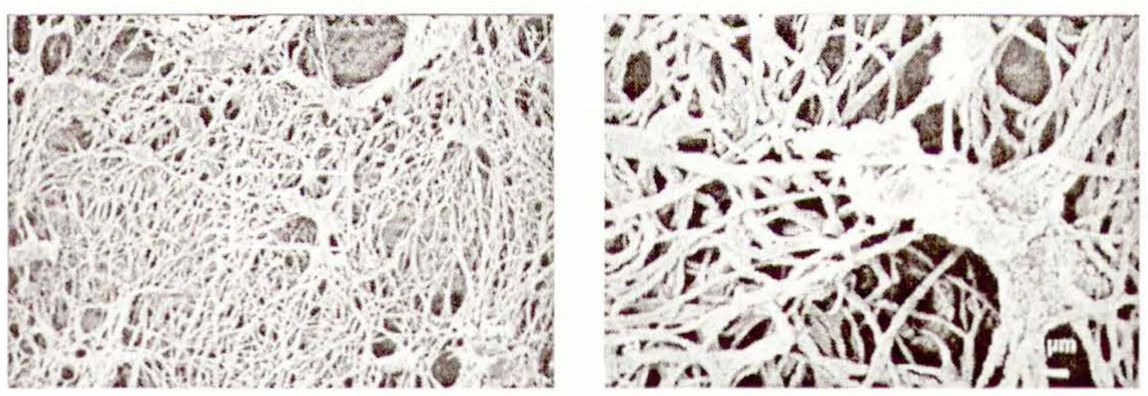

FIGURE 4. A scanning electron micrograph showing the replicas of lacunae and canaliculi in situ in mandibular bone from a young subject aged 22 years. The inset shows enlarged lacunae identified by a rectangle. This micrograph illustrates the interconnectivity of the connected cellular network (CCN). Copied from [195]. 
bone from a young subject aged 22 years. The inset of Fig. 4 shows enlarged lacunae identified by a rectangle.

The touching cell processes of two neighboring bone cells contain gap junctions $[23,24,25,26,27,28,29,30]$. A gap junction is a channel connecting two cells. The location of the gap junction is indicated by the arrowheads in Fig. 2. The walls of the channel consist of matching rings of proteins piercing the membrane of each cell, and when the rings associated with two cells connect with each other, the cell-to-cell junction is formed. This junction allows ions and compounds of low molecular weight to pass between the two cells without passing into the extracellular space. The proteins making up a gap junction are called connexins; in bone the protein is either connexin 43 or 45 , with 43 predominating (the number refers to the size of the proteins calculated in kilodaltons) [31,32]. A ring of connexins in one cell membrane is generally called a connexon or hemichannel. Both mechanical strain and fluid shear stress cause increased expression of the connexin 43 in vascular tissues [33]. In cardiac tissue the turnover rate of connexin 43 is very rapid [34]. The rapid dynamics of gap junction turnover and the plasticity of gap junction expression in response to various stimuli offer the possibility for remodeling of the intercellular circuits both within and between communication compartments in the cardiovascular system [35]. In bone, gap junctions connect superficial osteocytes to periosteal and endosteal osteoblasts. All osteoblasts are similarly interconnected laterally on a bony surface; perpendicular to the bony surface, gap junctions connect periosteal osteoblasts with preosteoblastic cells, and these, in turn, are similarly interconnected. Effectively, each CCN is a true syncytium $[25,27,28,36]$. Gap junctions are found where the plasma membranes of a pair of markedly lapping canalicular processes meet [36]. In compact bone, canaliculi cross the cement lines that form the outer boundary of osteons. Thus extensive communication exists between osteons and interstitial regions [37].

Bone cells are electrically active $[38,39,40,41,42]$. In addition to permitting the intercellular transmission of ions and small molecules, gap junctions exhibit both electrical and fluorescent dye transmission [43, 44, 45, 46]. Gap junctions are electrical synapses, in contradistinction to interneuronal, chemical synapses; and, significantly, they permit bi-directional signal traffic (e.g., biochemical, ionic, electrical etc.). In a physical sense, the CCN represents the hard wiring $[20,21,22,47]$ of bone tissue. 


\section{Mechanosensation in Bone: Stimuli}

The stimulus for bone remodeling is defined as that particular aspect of the bone's stress or strain history that is employed by the bone to sense its mechanical load environment and to signal for the deposition, maintenance or resorption of bone tissue. The bone tissue domain or region over which the stimulus is felt is called the sensor domain. When an appropriate stimulus parameter exceeds threshold values, loaded tissues respond by the triad of bone adaptation processes: deposition, resorption and maintenance. The CCN is the site of intracellular stimulus reception, signal transduction and intercellular signal transmission. It is thought that stimulus reception occurs in the osteocyte [20], and that the CCN transduces and transmits the signal to the surface lining or osteoblast. The osteoblasts alone directly regulate bone deposition and maintenance, and indirectly regulate osteoclastic resorption [48]. The possible role of the osteoblast as a stimulus receptor has not yet been thoroughly investigated [49]. Although it is reasonably presumed that initial mechanosensory events occur at the plasma membrane of the osteocytic soma and/or canalicular processes, the initial receptive, and subsequent transductive, processes are not well understood.

It follows that the true biological stimulus, although much discussed, is not precisely known. A variety of mechanical loading stimuli associated with ambulation (at a frequency of one to two $\mathrm{Hz}$ ) have been considered for bone remodeling. The majority has followed Wolff $[2,3]$ in suggesting that some aspect of the mechanical loading of bone is the stimulus. The mechanical stimuli suggested include strain [50], stress [2,3], strain energy [51, 52], strain rate $[53,54,55,56,57,58,59]$, and fatigue microdamage $[60,61]$. In some cases the time-averaged values of these quantities are suggested as the mechanical stimulus, and in others the amplitudes of the oscillatory components and/or peak values of these quantities are the candidates for the mechanical stimulus. Two-dozen possible stimuli were compared in a combined experimental and analytical approach [62]. The data supported strain energy density, longitudinal shear stress and tensile principal stress or strain as stimuli; no stimulus that could be described as rate dependent was among the two dozen possible stimuli considered in the study. For a consideration of the stimulus in microgravity see [63].

The case for strain rate as a remodeling stimulus has been building over the last quarter century. The animal studies of Hert and his coworkers 
$[53,54,55]$ suggested the importance of strain rate. Experiments $[57,58,59]$ have quantified the importance of strain rate over strain as a remodeling stimulus. The studies $[64,65,66]$ directed at the understanding of the cellular mechanism for bone remodeling have suggested that the prime mover is the bone strain rate driven motion of the bone fluid whose signal is transduced by osteocytes. In the model $[64,65,66]$ developed, the shear stress from the bone fluid flow over the osteocytic processes in the canaliculi is a cellular mechanism-based model suggesting strain rate as a stimulus. A later study [67] showed that it was not shear stress applied directly to the cell membrane, but rather the force created by fluid drag on the fibers of the glycocalyx of the cell transmitted to the cell membrane. This study will be described in grater detail in the section on strain amplification. A recent study [68] that showed bone deposition to be related to strain gradients actually demonstrates a dependence upon strain rate if the model developed in $[64,65,66]$ is realistic.

In experiments with cultured cells it has been shown that osteocytes, but not periosteal fibroblasts, are extremely sensitive to fluid flow, resulting in increased prostaglandin as well as nitric oxide production $[69,70]$. Three different cell populations, namely osteocytes, osteoblasts, and periosteal fibroblasts, were subjected to two stress regimes, pulsatile fluid flow and intermittent hydrostatic compression (IHC) [69]. Intermittent hydrostatic compression was applied at $0.3 \mathrm{~Hz}$ with a $13 \mathrm{kPa}$ peak pressure. The pulsatile fluid flow was a fluid flow with a mean shear stress of $0.5 \mathrm{~Pa}$ with cyclic variations of $0.02 \mathrm{~Pa}$ at $5 \mathrm{~Hz}$. The maximal hydrostatic pressure rate was $130 \mathrm{kPa} / \mathrm{sec}$ and the maximal fluid shear stress rate was $12 \mathrm{~Pa} / \mathrm{sec}$. Under both stress regimes, osteocytes appeared more sensitive than osteoblasts, and osteoblasts more sensitive than periosteal fibroblasts. However, despite the large difference in peak stress and peak stress rate, pulsatile fluid flow was more effective than intermittent hydrostatic compression. Osteocytes, but not the other cell types responded to 1 hour pulsatile fluid flow treatment with a sustained prostaglandin $\mathrm{E}_{2}$ upregulation lasting at least one hour after pulsatile fluid flow was terminated. By comparison, IHC needed 6 hours treatment before a response was found. These results suggested that osteocytes are more sensitive to mechanical stress than osteoblasts, which are again more sensitive than periosteal fibroblasts. Furthermore, osteocytes appeared particularly sensitive to fluid shear stress, more so than to hydrostatic stress. These conclusions are in agreement with the theory that osteocytes are the 
main mechanosensory cells of bone, and that they detect mechanical loading events by the canalicular flow of interstitial fluid which results from that loading event. The model developed in $[64,65,66]$ used Biot's porous media theory to relate loads applied to a whole bone to the flow of canalicular interstitial fluid past the osteocytic processes. These calculations predicted fluid induced shear stresses of $0.8-3 \mathrm{~Pa}$, as a result of peak physiological loading regimes. The findings that bone cells in vitro actually respond to fluid shear stress of $0.2-6 \mathrm{~Pa}[69,70,71,72,73]$ lend experimental support to the model $[64,65,66]$.

Osteocytes also rapidly release nitric oxide in response to stress $[70,74]$ and this NO response seems to be required for the stress-related prostaglandin release [70]. Therefore, the behavior of osteocytes compares to that of endothelial cells which regulate the flow of blood through the vascular system, and also respond to fluid flow of $0.5 \mathrm{~Pa}$ with increased prostaglandin and nitric oxide production [75]. The response of endothelial cells to shear stress is likely related to their role in mediating an adaptive remodeling of the vasculature, so as to maintain constant endothelial fluid shear stress throughout the arterial site of the circulation [76].

Skeletal muscle contraction is a typical bone-loading event and has been suggested $[77,78,79]$ as a stimulus. Frequency is one of the critical parameters of the muscle stimulus and it serves to differentiate this stimulus from the direct mechanical loads of ambulation which occur at a frequency of one to two $\mathrm{Hz}$. The frequency of contracting muscle in tetanus is from $15 \mathrm{~Hz}$ to a maximum of $50-60 \mathrm{~Hz}$ in mammalian muscle [80]. It has been observed $[81,82]$ that these higher order frequencies, significantly related to bone adaptational responses, are [83] "... present within the [muscle contraction] strain energy spectra regardless of animal or activity and implicate the dynamics of muscle contraction as the source of this energy band." The close similarity of muscle stimulus frequencies to bone tissue response frequencies is noted below.

\section{Strain Amplification}

There is a fundamental paradox in the physiology of bone mechanosensation. The paradox (Fig. 5) is that the strains applied to whole bone (i.e., tissue level strains) are much smaller $(0.04 \%$ to $0.3 \%)$ than the strains $(1 \%$ to $10 \%$ ) that are necessary to cause bone signaling in deformed cell cul- 


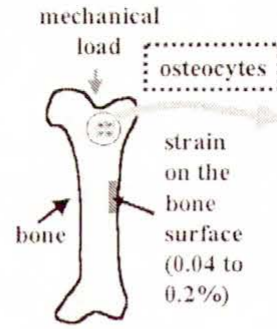

(a)

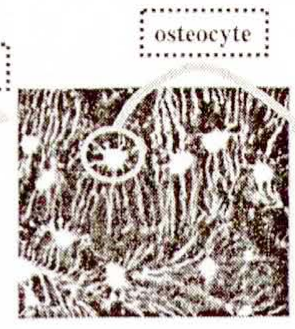

(b)

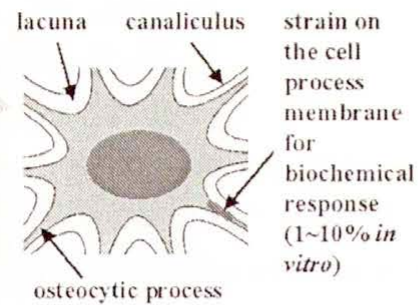

(c)

Figure 5. Paradox addressed in mechanosensation. (a) An illustration of the small strains that the whole bone experiences, strains that are in the range 0.04 to 0.3 percent and seldom exceed 0.1 percent. The last two panels, (b) photomicrograph of osteocytes encased in bone matrix (c) osteocyte in lacuna, illustrate that large strains (1 to 10 percent) on cell membrane are needed to induce biochemical intracellular response in vitro. The paradox in the bone mechanosensing system is that the strains that activate the bone cells are two orders of magnitude larger than the strains to which the whole bone organ is subjected. Previously published in [67].

tures $[59,84]$. Osteocytes (Fig. 2) are believed to be the critical mechanical sensor cells $[20,85]$, although the mechanism by which osteocytes perceive mechanical load is not known. One widely held idea is that cell membrane stretch occurs as a direct result of surrounding tissue deformation. If this is the case, then strain on osteocyte membranes should be comparable to the bone tissue strain. However, in vitro studies show that in order to induce any cellular response by direct mechanical deformation of bone cells, deformations need to be one to two orders of magnitude larger than the bone tissue strains normally experienced by the whole bone in vivo $[67,86]$. Similar cell strain magnitudes are needed to activate fibroblasts and chondrocytes ( 15\%) [87,88], suggesting that in their sensitivity to mechanical strain, osteocytes may not be different from other connective tissue cells. However, in bone the larger strains needed to stimulate osteocytes cannot be derived directly from matrix deformations, as they would cause bone fracture. Thus, in bone there is an inherent contradiction between material and biological stimulation requirements. A hypothesis and model to deal with this contradiction is given in [67].

The flow of bone fluid due to mechanical loading through the lacunocanalicular system is an important aspect of the model presented in [67]. Between the osteocyte cell process membrane and canalicular wall is the pericellular space through which the bone fluid flows (Fig. 2, Fig. 3). A pericellular 
organic matrix appears to fill the space $[89,90]$. This matrix is supported by transverse fibrils [91] that appear to anchor and center the cell process in its canaliculus. When a whole bone is deformed, the deformation-induced pressure gradient will cause bone fluid to flow in the pericellular space of the lacunar-canalicular system $[64,65,66,92,93,94]$ and induce a drag force on the matrix fibers.

The effect of fluid drag forces on the pericellular matrix and its coupling to the intracellular actin cytoskeleton and the strain amplification that results from this coupling, was examined in [67]. The fluid drag on an attached pericellular matrix causes a circumferential (hoop) strain in the membranecytoskeleton of the cell process. The model in [67] shows that, for the loading range 1 to $20 \mathrm{MPa}$ and frequency range $1-20 \mathrm{~Hz}$, it is, indeed, possible to produce cellular level strains in bone that are up to 100 fold greater than normal tissue level strains ( $0.04 \%$ to $0.3 \%)$. Thus, the strain in the cell process membrane due to the loading can be of the same order as the in vitro strains measured in cell culture studies where intracellular biochemical responses are observed for cells on stretched elastic substrates.

An idealized model for an individual canaliculus with its central cell process is a tube containing a centrally positioned osteocyte process and its surrounding fluid annulus filled with a mesh-like pericellular matrix is shown in Fig. 6. For the pericellular component, only two structural elements are critical for this mechanical model: 1) a space filling pericellular matrix with a fiber spacing $\Delta$ that is sufficiently small, and 2) transverse fibrils which tether the cell process to the canalicular wall. From a mechanics point of view, any matrix, which has these two characteristics, should function equivalently, although the degree of strain amplification will change with the fiber spacing $\Delta$. There is growing evidence to support this basic structure. First, a space filling pericellular matrix surrounding osteocytes is well-established $[89,90,91,95,96]$. Second, transverse tethering elements were first clearly identified in Fig. 3 in [91]. The pericellular space surrounding the osteocyte process varies from $14 \mathrm{~nm}$ to $100 \mathrm{~nm}[97,98,99]$, depending on species, age, age of osteocyte, histological bone type, skeletal location etc. As yet unreported electron microscopy studies by Lidan You on adult mice indicate a pericellular space of $30-50 \mathrm{~nm}$. Lidan You also observed that the cell process is invariably located at the center of the canalicular cross-section suggesting that the transverse fibrils are tension elements that anchor and position the cell process within the canaliculus. 
(a)

(b)

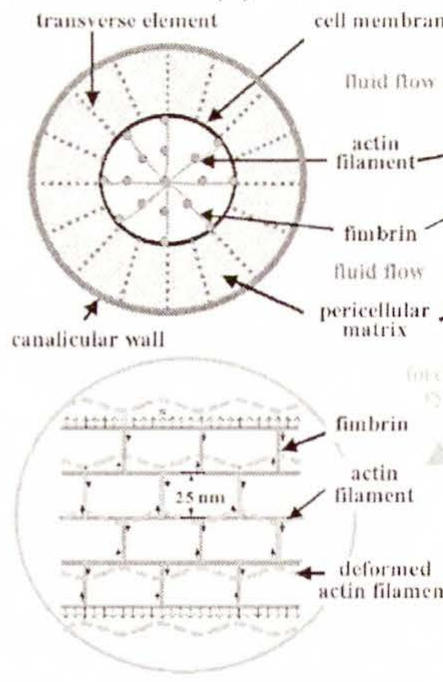

(c) deformed ecll membrane
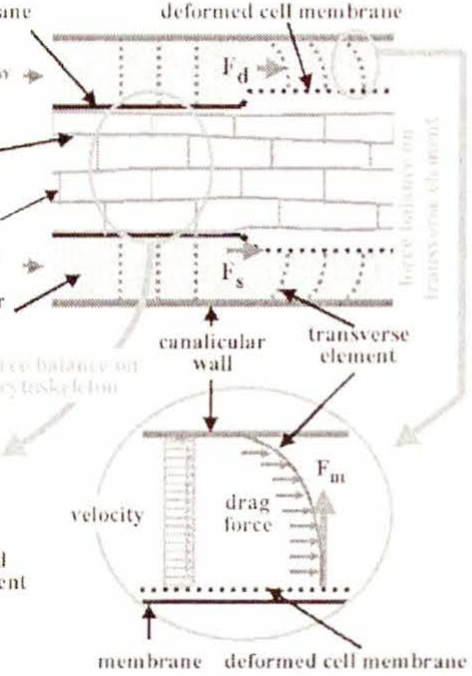

(d)

Figure 6. Schematic model showing the structure of the pericellular matrix (PM), the intracellular actin cytoskeleton inside the process and the connection between the PM and the IAC (intracellular actin cytoskeleton). (a) transverse cross-section of canaliculus showing the fluid annular shape of the region and transverse (radial) pericellular fibers. (b) longitudinal cross-section before and after the transverse elements are deformed by the flow. (c) schematic of the cell process cytoskeletal structure in longitudinal axial section used to estimate the Young's modulus in the radial (vertical) direction. Since the length of the cell process is 300 times its radius, it is considered infinite in the longitudinal (horizontal) direction. The axial actin filaments shown are modeled as continuous infinite beams with two types of loadings depending on whether the actin filaments are peripheral or interior. The small vertical arrows indicate the direction of the loading. The (fimbrin) links between these infinitely long beams are considered to be rigid. (d) Force balance on a transverse element. Previously published in [67].

Both albumin and proteoglycan exist in the pericellular space $[89,100]$. The effective diameter of albumin is approximately $7 \mathrm{~nm}$, similar to the spacing of glycosaminoglycans (GAG) side chains along a proteoglycan monomer [101]. The model of Weinbaum and Cowin $[64,65,66]$ suggested that the value of pore size leads to shear stresses of 0.5 to $3.0 \mathrm{~Pa}$ for mechanical loads in the physiological range and good agreement with the experimental data for the relaxation time of stress generated potentials (SGP) in bone under four point bending $[102,103,104]$. A pericellular matrix with a most likely pore size of $7 \mathrm{~nm}$ was assumed for the model in [67]. 
Finally, the matrix must be attached to the cell process and the canalicular wall in order for the drag force to be transmitted to the membrane and its underlying intracellular actin cytoskeleton. If such linker molecules are present, drag forces exerted on the matrix fibers will produce a tensile stress on these linker molecules that, in turn, will produce radial (hoop) strain in the intracellular actin cytoskeleton as schematically shown in Fig. 6. Possible candidates for these attachment molecules are CD44, laminin, and various integrins. $[105,106]$.

Osteocyte processes contain a space filling actin bundle [99, 107], whose actin filaments are cross-linked at regular intervals along the axis of the process by a linker molecule recently identified as fimbrin [107] as shown in Fig. 6c. The axial actin filaments are approx. $6 \mathrm{~nm}$ in diameter. Fimbrin is also found in intestinal microvilli [108] as well as non-intestinal cell microvilli [109]. The typical spacing of fimbrin cross-linked actin filaments in microvilli is approximately $25 \mathrm{~nm}$ [110]. This spacing is consistent with the EM observation in [99] and [107] for an osteocyte process.

The strain amplification ratio $e_{r}$ is defined as the ratio of the hoop strain in the cell process membrane to the bone surface strain at the osteonal lumen. The effect of frequency on the strain amplification ratio at different loading magnitudes is shown in Fig. 7, where the strain amplification ratio is plotted

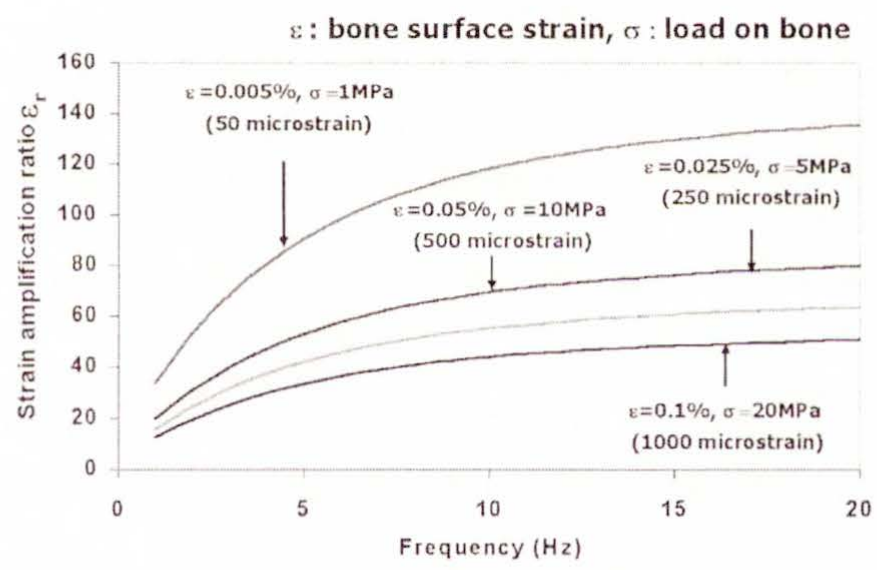

Figure 7. Strain amplification: A plot of the strain amplification ratio $e_{r}$ as a function of the load frequency for different load magnitudes. Strain amplification ratio is defined as the ratio of the hoop strain in the cell process membrane to the bone surface strain at the osteonal lumen. e is the strain on the whole bone; $s$ is the load on the whole bone. Previously published in [67]. 
against the loading frequency from 1 to $20 \mathrm{~Hz}$. The hoop strain is calculated at the position of maximum flow or pressure gradient, which is located at the surface of the Haversian canal. Thus, the strain amplification ratio shown in Fig. 7 can be considered as an upper bound. The curves show a monotonic increase in the amplification ratio as a function of frequency for a prescribed loading. One observes that the amplification ratio varies from 19 to 122 and depends significantly on the magnitude of the loading. When the loading magnitude is one $\mathrm{MPa}$, corresponding to 50 mstrain at the osteonal lumen, the strain amplification ratio $e_{r}$ is 122 at $20 \mathrm{~Hz}$. For this loading the cell process strain is 0.68 percent. For a $20 \mathrm{MPa}$ load at $20 \mathrm{~Hz}, e_{r}=44$ and the cell process strain is 4.9 percent. The corresponding values of $e_{r}$ at $1 \mathrm{~Hz}$ for a 1 and $20 \mathrm{MPa}$ load are 51 and 19 and the corresponding strains are 0.29 and 2.1 percent, respectively. Strains of the order of 0.3 percent or greater fall in the range where cellular level biochemical responses have been observed in vitro in four point bending [74].

\section{Mechanosensation in Bone: Reception and Transduction}

The osteocyte has been suggested as the stimulus sensor, the receptor of the stimulus signal [20]; histologic and physiologic data are consistent with this suggestion $[90,96,111]$. The placement and distribution of osteocytes in the CCN three-dimensional array is architecturally well suited to sense deformation of the mineralized tissue encasing them [112]. Since only a population of cells, and not an individual receptor [113], can code unambiguously, the osteocytes in the CCN are potential mechanoreceptors by virtue of their network organization.

Osteocytic mechanotransduction may involve a number of different processes or cellular systems. These processes include stretch- and voltage-activated ion channels, cyto-matrix sensation-transduction processes, cyto-sensation by fluid shear stresses, cyto-sensation by streaming potentials and exogenous electric field strength. Each of these processes or cellular systems is discussed below.

\subsection{Stretch- and Voltage-Activated Ion Channels}

The osteocytic plasma membrane contains stretch-activated ion channels $[11,114,115,116,117,118,119]$ that are also found in many other cell types $[120,121]$. When activated in strained osteocytes, they permit passage of 
certain ions $[120,121]$, including $\mathrm{K}^{+}, \mathrm{Ca}^{2+}, \mathrm{Na}^{+}$and $\mathrm{Cs}^{+}$. Such ionic flow may, in turn, initiate cellular electrical events; e.g., bone cell stretch-activated channels may modulate membrane potential as well as $\mathrm{Ca}^{2+}$ ion flux $[11,122]$. Rough estimates of osteocytic mechanoreceptor strain sensitivity have been made [20], and the calculated values cover the morphogenetically significant strain range of $0.1 \%$ to $0.3 \%$ in the literature $[57,84,123]$. This appears to be too low a strain to open a stretch-activated ion channel.

As in most cells, the osteocytic plasma membrane contains voltage-activated ion channels, and transmembrane ion flow may be a significant osseous mechanotransductive process $[40,124,125,126]$. It is also possible that such ionic flow generates osteocytic action potentials, capable of transmission through gap junctions [44].

\subsection{Cyto-Matrix Sensation-Transduction Processes}

The mineralized matrix of bone tissue is strained when loaded. Macromolecular mechanical connections between the extracellular matrix and the osteocytic cell membrane exist and these connections may be capable of transmitting information from the strained extracellular matrix to the bone cell nuclear membrane. The basis of this mechanism is the physical continuity of the transmembrane integrin molecule, which is connected extracellularly with the macromolecular collagen of the organic matrix and intracellularly with the cytoskeletal actin. The latter, in turn, is connected to the nuclear membrane $[91,127,128,129,130,131,132,133,134,135,136,137,138,139]$. It is suggested that such a cytoskeletal lever chain, connecting to the nuclear membrane, can provide a physical stimulus able to activate the osteocytic genome [26], possibly by first stimulating the activity of such components as the c-fos genes [26, 128, 135, 140, 142, 143, 144, 145, 146, 147, 148].

\subsection{Cyto-Sensation by Fluid Shear Stresses}

An hypothesis concerning the mechanism by which the osteocytes housed in the lacunae of mechanically loaded bone sense the load applied to the bone by the detection of dynamic strains was suggested in [64,65,66]. It was proposed that the osteocytes are stimulated by relatively small fluid shear stresses acting on the membranes of their osteocytic processes. A hierarchical model of bone tissue structure that related the cyclic mechanical loading applied to the whole bone to the fluid shear stress at the surface of the osteo- 
cytic cell process was presented in $[64,65,66]$. In this model the sensitivity of strain detection is a function of frequency; in the physiological frequency range $(1-20 \mathrm{~Hz})$, associated with either locomotion $(1-2 \mathrm{~Hz})$ or the maintenance of posture $(15-30 \mathrm{~Hz})$, the fluid shear stress is nearly proportional to the product of frequency and strain. Thus if bone cells respond to strains on the order of $0.1 \%$ at frequencies of one or two $\mathrm{Hz}$, they will also respond to strains on the order of $0.01 \%$ at frequencies of $20 \mathrm{~Hz}$. The fluid shear stresses would also strain the macromolecular mechanical connections between the cell and the extracellular bone matrix mentioned in the section above; thus fluid shear stress is also potentially capable of transmitting information from the strained matrix to the bone cell nuclear membrane, where it can effectively regulate its genomic functions.

Several investigators $[92,147,149]$ have examined other aspects of the lacunar-canalicular porosity using simple circular pore models and have attempted to analyze its possible physiological importance. These studies have primarily emphasized the importance of the convective flow in the canaliculi between the lacunae as a way of enhancing the supply of nutrients between neighboring osteocytes. Previous studies on the relaxation of the excess pore pressure have been closely tied to the strain generated potentials (SGP) associated with bone fluid motion. The SGP studies are briefly reviewed below.

\subsection{The Cyto-Sensation Is Actually Caused by Fluid Drag Rather Than Fluid Shear}

The model of You et al. [67] discussed in the previous section was used to make a second interesting prediction. It demonstrated that in any cellular system where cells are subject to fluid flow and tethered to more rigid supporting structures, the tensile forces on the cell due to the drag forces on the tethering fibers may be many times greater than the fluid shear force on the cell membrane. As proposed in $[64,65,66]$ the fluid flow will also induce shear stress on the cell process membrane. These stresses have been shown to mechanically stimulate bone cells [71,72]. In the case of the extension [67] of the model proposed in $[64,65,66]$ for fluid flow in the canaliculus, the drag force on the matrix is larger than the fluid shear force. The matrix must be attached to the cell process and the canalicular wall in order for the drag force to be transmitted to the membrane and its underlying intracellular actin cytoskeleton. 


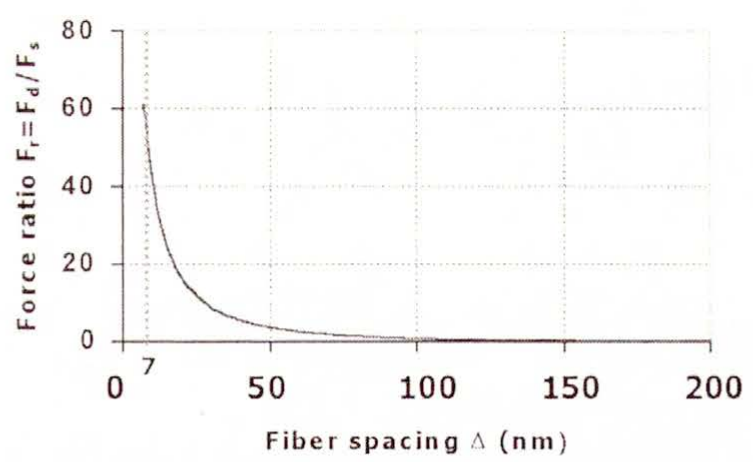

Figure 8. The relationship between force ratio $F_{r}$ and average fiber spacing $\Delta$. Note the force ratio at $\Delta=7 \mathrm{~nm}$ is $19.6 \mathrm{~nm}$ is typical of the average spacing of GAG side chains along a core protein and the effective diameter of the albumin molecule which is known to be sieved by an equivalent matrix in capillary endothelium. This varies between 5 and $12 \mathrm{~nm}$. The force ratio $F_{r}$ is defined as the ratio of the drag force on the fibers to the shear force on the cell process membrane per unit length of cell process. Previously published in [67].

The force ratio $F_{r}$ is defined as the ratio of the drag force on the fibers to the shear force on the cell process membrane per unit length of cell process. The relationship between the force ratio $F_{r}$ and the average fiber spacing $\Delta$ is plotted in Fig. 8. Note the force ratio at $\Delta=7 \mathrm{~nm}$ is $19.6 . \Delta=7 \mathrm{~nm}$ is typical of the average spacing of GAG side chains along a core protein and the effective diameter of the albumin molecule that is known to be sieved by an equivalent matrix in capillary endothelium. This varies between 5 and $12 \mathrm{~nm}$.

\subsection{Cyto-Sensation by Streaming Potentials}

The fact that the extracellular bone matrix is negatively charged due to its proteins means that a fluid electrolyte bounded by the extracellular matrix will have a diffuse double layer of positive charges. When the fluid moves, the excess positive charge is convected, thereby developing streaming currents and streaming potentials (Fig. 9). The cause of the fluid motion is the deformation of the extracellular matrix due to whole bone mechanical loading. Pollack and coworkers $[102,103,150]$ have laid an important foundation for explaining the origin of strain-generated potentials (SGP). However the anatomical site in bone tissue that is the source of the experimentally observed SGPs is not agreed upon. It was concluded in [103] that this site 


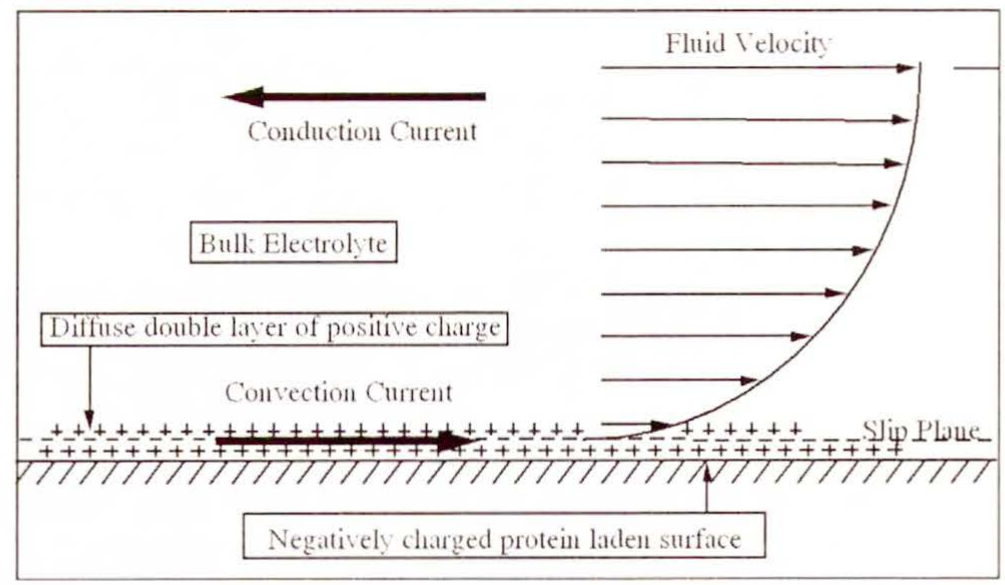

FIgURE 9. Strain-generated potentials (SGP's) in bone fluid channels. The source of SGP's stems from the fact that the extracellular bone matrix is negatively charged due to negative fixed charges on carbohydrates and proteins; thus a fluid electrolyte bounded by the extracellular matrix will have a diffuse double layer of positive charges. When the fluid moves, the excess positive charge is convected, thereby developing streaming currents and streaming potentials. A conduction current is thought to balance the convection current. The bulk electrolyte is neutral with respect to charge. The fluid motion is caused by the pore fluid pressure gradients induced by the deformation of the extracellular matrix due to whole bone mechanical loading.

was the collagen-hydroxyapatite porosity of the bone mineral, because small pores of approximately $16 \mathrm{~nm}$ radius were consistent with their experimental data if a poroelastic-electrokinetic model with unobstructed and connected circular pores was assumed [102]. However in [66] it was shown that the data presented in $[103,104,151]$ are also consistent with the larger pore space $(100 \mathrm{~nm})$ of the lacunar-canalicular porosity being the anatomical source site of the SGPs if the hydraulic drag and electrokinetic contribution associated with the passage of bone fluid through the surface matrix (glycocalyx) of the osteocytic process are accounted for. The mathematical models presented in $[102]$ and $[64,65,66,67]$ are similar in that they combine poroelastic and electrokinetic theory to describe the phase and magnitude of the SGP. The two theories differ in the description of the interstitial fluid flow and streaming currents at the microstructural level and in the anatomical structures that determine the flow. In $[64,65,66]$ this hydraulic resistance resides in the fluid annulus that surrounds the osteocytic processes, i.e. the cell membrane of the osteocytic process, the walls of the canaliculi and the glycocalyx (also called 
the surface matrix or capsule) that exists in this annular region. In [66] the presence of the glycocalyx increases the SGPs and the hydraulic resistance to the strain-driven flow. The increased SGP matches the phase and amplitude of the measured SGPs. In the [102] model this fluid resistance and SGP are achieved by assuming that an open, continuous small pore structure $(\approx 16 \mathrm{~nm}$ radius) exists in the mineralized matrix. The poroelastic model of $[64,65,66]$ for bone fluid flow has been developed further $[152,153,154,155,156]$ and a review of the related poroelastic literature has appeared [93].

Experimental evidence indicating that the collagen-hydroxyapatite porosity of the bone mineral is unlikely to serve as the primary source of the SGP is obtained from several sources, including the estimates of the pore size in the collagen-hydroxyapatite porosity and permeability studies with different size labeled tracers in both mineralized and unmineralized bone. Such permeability studies clearly show time-dependent changes in the interstitial pathways as bone matures. At the earliest times, the unmineralized collagenproteoglycan bone matrix is porous to large solutes. The studies with ferritin (10 $\mathrm{nm}$ in diameter) in two-day old chick embryo [157] show a continuous halo around primary osteons five minutes after the injection of this tracer. The halo passes right through the lacunar-canalicular system suggesting that, before mineralization, pores of the size predicted in [103] (radii $\approx 16 \mathrm{~nm}$ ) can exist throughout the bone matrix. In contrast a report of an experiment [158] using this same tracer in adult dogs also found a fluorescent halo surrounding the Haversian canals; however this halo was not continuous but formed by discrete lines suggesting that the pathways were limited to discrete pores whose spacing was similar to that observed for canaliculi. This conclusion is supported by the studies [159] in the alveolar bone of five-day-old rats using the much smaller tracer, microperoxidase (MP) (2 nm). These studies clearly showed that the MP only penetrated the unmineralized matrix surrounding the lacunae and the borders of the canaliculi (see Fig. 13 of this study) and was absent from the mineralized matrix. Using more mature rats, the study of [160] confirmed the failure of the small $(2 \mathrm{~nm})$ MP tracer to penetrate the mineralized matrix tissue from the bone fluid compartments.

\subsection{Exogenous Electric Field Strength}

Bone responds to exogenous electrical fields [161]. While the extrinsic electrical parameters are unclear, field strength may play an important role 
$[161,162]$. A significant parallelism exists between the parameters of exogenous electrical fields and the endogenous fields produced by muscle activity. Bone responds to exogenous fields in an effective range of $1-10 \mathrm{mV} / \mathrm{cm}$, strengths that are on the order of those endogenously produced in bone tissue during normal (muscle) activity [163].

\section{Mechanosensation in Bone: Signal Transmission}

From a communications viewpoint the CCN is multiply noded (each osteocyte is a node) and multiply connected (Fig. 4). Each osteocytic process is a connection between two osteocytes, and each osteocyte is multiply connected to a number of osteocytes that are near neighbors. Cell-to-cell communication is considered first below, then some speculative considerations of the ability of the CCN to compute as well as signal are described. It is useful to note the possibility that bone cells, like neurons, may communicate intercellular information by volume transmission, a process that does not require direct cytological contact, but rather utilizes charges in the environment $[164,165,166]$.

\subsection{Cell-to-Cell Communication}

In order to transmit a signal over the CCN one osteocyte must be able to signal a neighboring osteocyte that will then pass the signal on until it reaches an osteoblast on the bone surface. There are varieties of chemical and electrical cell-to-cell communication methods [167]. The passage of chemical signals, such as $\mathrm{Ca}^{2+}$, from cell to cell appears to occur at a rate that would be too slow to respond to the approximately $30 \mathrm{~Hz}$ signal associated with muscle firing. The focus here is on electrical cell-to-cell communication. A cable model for cell-to-cell communication in an osteon has been formulated $[152,153]$. The spatial distribution of intracellular electric potential and current from the cement line to the lumen of an osteon was estimated as the frequency of the loading and conductance of the gap junction were altered. In this model the intracellular potential and current are driven by the mechanically induced strain generated streaming potentials (SGPS) produced by the cyclic mechanical loading of bone. The model differs from earlier studies [168] in that it pursues a more physiological approach in which the microanatomical dimensions of the connexon pores, osteocytic processes and the distribution of cellular membrane area and capacitance are used to quantita- 
tively estimate the leakage of current through the osteoblast membrane, the time delay in signal transmission along the cable and the relative resistance of the osteocytic processes and the connexons in their open and closed states. The model predicts that the cable demonstrates a strong resonant response when the cable coupling length approaches the osteonal radius. The theory also predicts that the pore pressure relaxation time for the draining of the bone fluid into the osteonal canal is of the same order as the characteristic diffusion time for the spread of current along the membrane of the osteocytic processes. This coincidence of characteristic times produced a spectral resonance in the cable at $30 \mathrm{~Hz}$. These two resonances lead to a large amplification of the intracellular potential and current in the surface osteoblasts, which could serve as the initiating signal for osteoblasts to conduct remodeling.

\subsection{Signal Processing and Integration}

When a physical representation of a CCN, such as Fig. 1, is viewed by someone familiar with communications there is often an intuitive response that the CCN may function as a neural network for processing the mechanical loading stimulus signals being felt over the network. That idea is explored here with no justification other than shared intuition. A CCN is operationally analogous to an artificial neural network in which massively parallel, or parallel distributed, signal processing occurs $[113,169,170]$. Fortunately the bases of connectionist theory are sufficiently secure to permit a biologically realistic CCN model [171, 172, 173, 174, 175].

A CCN consists of a number of relatively simple, densely interconnected, processing elements (bone cells), with many more interconnections than cells. Operationally these cells are organized into layers: an initial input, a final output and one or more intermediate or hidden layers. However such networks need not be numerically complex to be operationally complex [176].

The operational processes are identical, in principle, for all bone cells in all layers. Each cell in any layer may simultaneously receive several weighted (i.e., some quantitative measure) inputs. In the initial layer these are the loading stimuli (mechanoreception). Within each cell independently, "... all the weighted inputs are then summed..." [177]. This net sum is then compared, within the cell, against some threshold value. If this liminal value is exceeded, a signal is generated (mechanotransduction in input layer cells) 
that is then transmitted identically to all the hidden layer cells (adjacent osteocytes) to which each initial layer cell is connected. Similar processes of weighted signal summation, comparison and transmission occur in these layers until final layer cells (osteoblasts) are reached. The outputs of these surface situated cells regulate the specific adaptation process of each group of osteoblasts [178]. All neighboring osteoblasts that carry out an identical bone adaptational process form a communication compartment, a cohort of structurally and operationally similar cells, since all these cells are interconnected by open, functional gap junctions. At the boundary between such compartments that are carrying out different adaptational processes, the intervening gap junctions are closed and are incapable of transmitting information. These boundaries are probably changing continuously as some of the cells have some down time $[35,43]$.

Information is not stored discretely in a $\mathrm{CCN}$, as is the case in conventional computers. Rather it is distributed across all or part of the network, and several types of information may be stored simultaneously. The instantaneous state of a CCN is a property of all of its cells and of their connections. Accordingly its informational representation is redundant, assuring that the network is fault, or error, tolerant; i.e., one or several inoperative cells causes little or no noticeable loss in network operations [177]

CCNs exhibit oscillation; i.e., iterative reciprocal (feedback) signaling between layers enables them to adjustively self-organize. This is related to the fact that CCNs are not preprogrammed, rather they learn by unsupervised training [179], a process involving the adaptation of the CCNs to the responses of the cytoskeleton to physical activity [141]. In this way the CCN adjusts to the customary mechanical loading of the whole bone [57]. In a CCN, structurally more complex attributes and behavior gradually self-organize and emerge during operation. These are not reducible; they are neither apparent nor predictable from a prior knowledge of the behavior of individual cells.

As noted above, gap junctions as electrical synapses permit bi-directional flow of information. This is the cytological basis for the oscillatory behavior of a CCN. The presence of sharp discontinuities between groups of phenotypically different osteoblasts is related also to an associated property of gap junctions, i.e., their ability to close and so prevent the flow of information $[180,181]$. Significantly, informational networks can also transmit inhibitory signals, a matter beyond our present scope [182]. 
It is suggested that a CCN displays the following attributes: developmentally it is self-organized and self-adapting and, in the sense that it is epigenetically regulated, it is untrained; operationally, it is a stable, dynamic system, whose oscillatory behavior permits feedback; in this regard, it is noted that a CCN operates in a noisy, non-stationary environment, and that it also employs useful and necessary inhibitory inputs.

The CCN permits a triad of histological responses to a (seemingly) unitary loading event. Although in this chapter, as in almost all the related literature, the organization of bone cells is treated as if it existed only in two dimensions, and as if bone tissue loadings occurred only at certain discrete loci, and that without consideration of loading gradients, the biological situation is otherwise. Given such a loading event, a three-dimensional bone volume, gradients of deformation must exist, and each osteocyte may sense correspondingly different strain properties. Moreover, it is probable that each osteocyte potentially is able to transmit three different signals in three different directions, some stimulatory and some inhibitory: such states have not yet been modeled [183, 184].

\subsection{A Tentative Mechanotransduction Synthesis}

The molecular lever mechanisms that permit muscle function to directly regulate the genomic activity of strained bone cells, including their phenotypic expression, when combined together with electric field effects and contraction frequency energetics, provides a biophysical basis for an earlier hypothesis of epigenetic regulation of skeletal tissue adaptation $[185,186,187,188]$.

It is probable $[189,190]$ that electrical and mechanical transductive processes are neither exhaustive nor mutually exclusive. While utilizing differing intermediate membrane mechanisms and/or processes, they share a common final pathway [191]; i.e., both mechanical and electrical transductions result in transplasma membrane ionic flow $(\mathrm{s})$, creating a signal(s) capable of intercellular transmission to neighboring bone cells via gap junctions $[64,65,66$, $152,153,192]$. These signals are inputs to a CCN, whose outputs regulate the bone adaptational processes.

The primacy of electrical signals is suggested here, since while bone cell transduction may also produce small biochemical molecules that can pass through gap junctions, the time-course of mechanosensory processes is believed to be too rapid for the involvement of secondary messengers $[11,17,193]$. As noted above, the passage of chemical signals, such as $\mathrm{Ca}^{2+}$, 
from cell to cell appears to occur at a rate that would be too slow to respond to the approximately $30 \mathrm{~Hz}$ signal associated with muscle firing.

\section{Mechanosensation in the Auditory System}

Hearing works by the ear detecting sound waves, converting them into neural signals and then sending the signals to the brain ${ }^{1)}$. The ear has three divisions: the external ear, the middle ear, and the inner ear (Fig. 10). The external ear collects sound waves and funnels them down the ear canal, where they vibrate the eardrum. Within the middle ear, the eardrum is connected to the middle ear bones. These are the smallest bones in the body, and they mechanically carry the sound waves to the inner ear. The eustachian tube connects the middle ear to the upper part of the throat, equalizing the air pressure within the middle ear to that of the surrounding environment. The inner ear contains the cochlea. This organ converts sound waves into neural signals. These signals are passed to the brain via the auditory nerve.

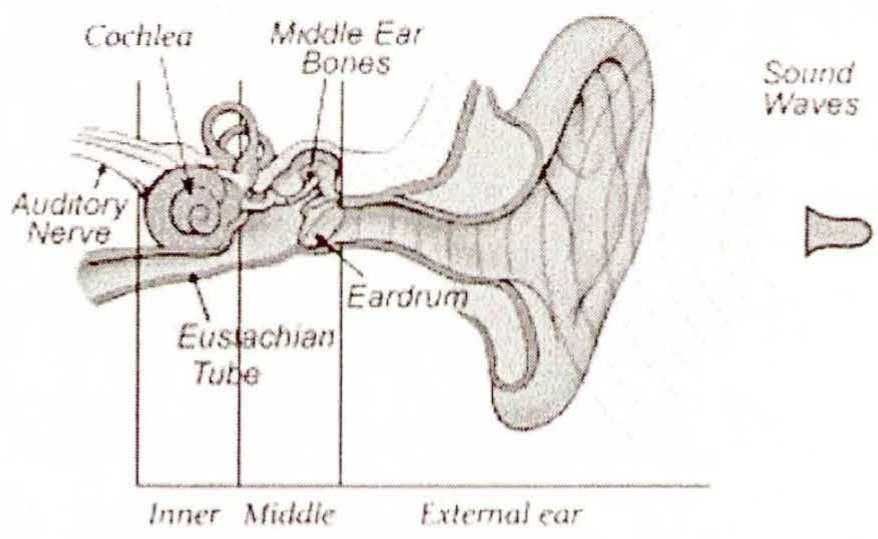

Figure 10. Anatomy of the ear. This figure is adapted from one on the website http://www.bcm.tmc.edu/oto/research/cochlea/Hearing/index.html associated with John S. Oghalai, M.D. in Otolaryngology at the Baylor College of Medicine.

\footnotetext{
1) The simple explanation of the process of hearing that follows is adapted from the website http://www.bcm.tmc .edu/oto/research/cochlea/Hearing/index.html associated with John S. Oghalai, M.D. in Otolaryngology at the Baylor College of Medicine.
} 


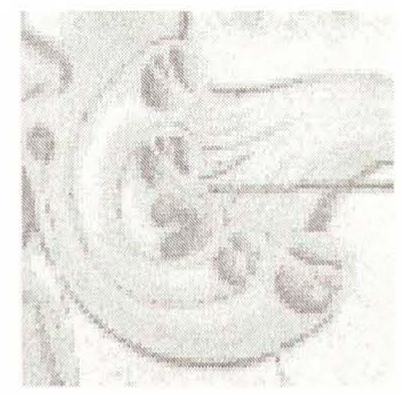

Figure 11. An exposed cross-section of the cochlea illustrating its three chambers. Adapted from an illustration on the website http://www.finchcms.edu/anatomy/histohome/lectures/ear/sld001.htm.

Mechanosensation occurs in the cochlea (Fig. 10). A section through the cochlea is shown in Fig. 11. Coiling around the inside of the cochlea, the organ of Corti (Fig. 12) contains the cells responsible for hearing, the hair cells (Fig. 13). There are two types of hair cells: inner hair cells and outer hair cells. These cells have stereocilia or "hairs" that stick out. The bottom of these cells is attached to the basilar membrane, and the stereocilia are in contact with the tectorial membrane. Inside the cochlea, sound waves cause the basilar membrane to vibrate up and down. This creates a shearing force

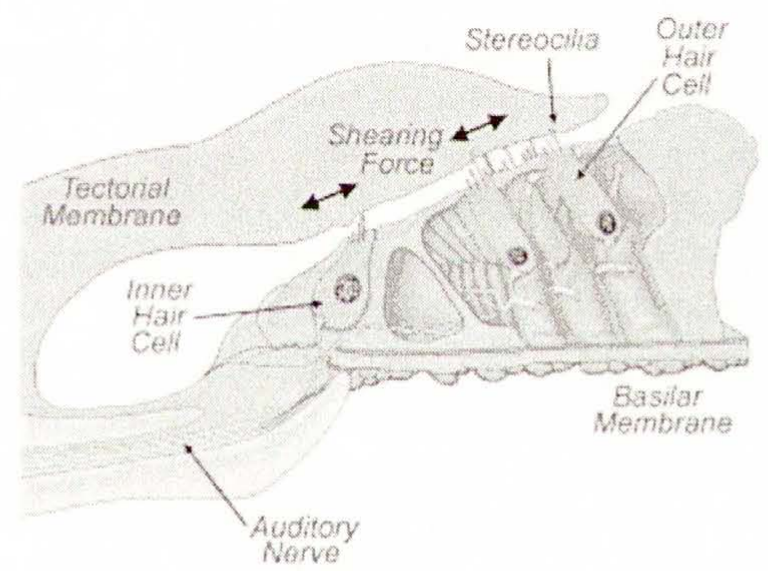

Figure 12. The organ of Corti. The organ of Corti is the structure that partitions the chambers of the cochlea illustrated in Fig.11. This figure is adapted from one on the website associated with John S. Oghalai, M.D. in Otolaryngology at the Baylor College of Medicine: http://www.bcm.tmc.edu/oto/research/cochlea/Hearing/index.html 


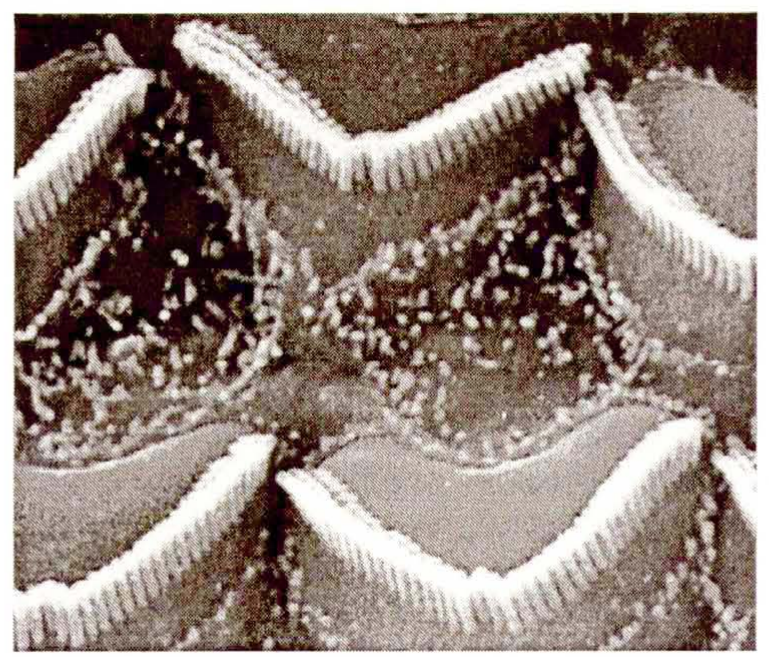

Figure 13. An array of hair cells.

(Fig. 12) between the basilar membrane and the tectorial membrane, causing the hair cell stereocilia to bend back and forth (Fig. 14). The movement of a hair cell's cilia bundle opens ion channels at the tips of the cilia (Fig. 14). When the bundle tilts to the right (middle panel of Fig. 14), tip links from the higher cilia pull up the gates of the ion channels on adjoining, shorter cilia. A close-up shows how a tip link between two cilia opens an ion channel on the shorter cilium. Even more highly magnified at the right of Fig. 14, the open channel allows ions into the cell. This leads to internal changes within the hair cells that create electrical signals. Auditory nerve fibers rest below the hair cells and pass these signals on to the brain. Therefore, the bending of the stereocilia is how hair cells sense sounds.

Outer hair cells have a special function within the cochlea. They are shaped cylindrically, like a can, and have stereocilia at the top of the cell (Fig. 13), and a nucleus at the bottom. When the stereocilia are bent in response to a sound wave, an electromotile response occurs. This means the cell changes in length. Therefore, with every sound wave, the cell shortens and then elongates. This pushes against the tectorial membrane, selectively amplifying the vibration of the basilar membrane. This allows us to hear very quiet sounds.

The similarities between the cytoplasmic processes of bones cells and the stereocilia of hair cells are that they both (1) measure mechanical deforma- 

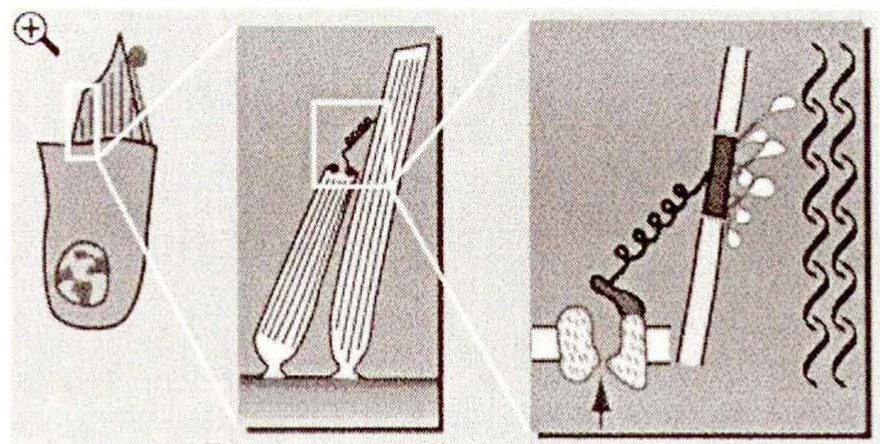

Figure 14. The movement of a hair cell's cilia bundle (left panel) opens ion channels at the tips of the cilia. When the bundle tilts to the right (middle panel), tip links from the higher cilia pull up the gates of the ion channels on adjoining, shorter cilia. This (still middle panel) close-up shows how a tip link between two cilia opens an ion channel on the shorter cilium. Even more highly magnified in the right panel, the open channel allows ions into the cell. This illustration is by Jennifer Jordan, RCW Communications, Inc. (adapted from a sketch by James Hudspeth, HHMI, University of Texas Southwestern Medical Center at Dallas).

tions (vibrations of a fluid domain), (2) communicate their measurement to a network, (3) do this with dendritic structures, (4) the dendrites of both cells are constructed of similar materials (e.g., actin and fimbrin) and (5) the initial signaling in both cases consists of opening ion channels. While the hair cells communicate their information to a network that feeds to the brain, the bones cells connect to a lower level network (CCN) with (potentially) local decision-making software.

\section{References}

1. J. WolfF, Uber der innere Architektur der Knochen und ihre Bedeutung fur die Frage vom Knochenwachstum, Arch. Path. Anat. Physio. Med., Virchovs Arch., 50:389-453, 1870.

2. J. WolfF, Das Gesetz der Transformation der Knochen, Hirschwald, Berlin 1892.

3. J. Wolff, The Law of Bone Remodelling, Springer, Berlin 1986.

4. H.M. Frost, The Laws of Bone Structure, Charles C. Thomas, Springfield, Illinois 1964. 
5. H.M. Frost, Tetracycline-based histological analysis of bone remodeling, Calcified Tissue Research, 3:211-237, 1969.

6. H.K. Uhthoff and Z.F.G. Jaworski, Bone loss in response to long term immobilization, J. Bone Joint Surgery, 60-B :420-429, 1978.

7. Z.F.G. Jaworski, M. Liskova-Kiar, and H.K. Uhthoff, Effect of long term immobilization on the pattern of bone loss in older dogs, J. Bone Joint Surgery, 62B : 104-110, 1980.

8. L.E. Lanyon, A.E. Goodship, C.J. Pye, and J.H. MacFie, Mechanically adaptive bone remodeling, J. Biomechanics, 15:141-154, 1982.

9. S.C. Cowin and M.L. Moss, Mechanosensory mechanisms in bone, [in:] Textbook of Tissue Engineering, $2^{\text {nd }}$ edition, pp.723-738, R.Lanza, R. Langer, and W.Chick, [Eds.], Academic Press, San Diego, California, 2000 .

10. E.L. Burger, J. Klein-Nulend, and S.C. Cowin, Mechanotransduction in bone, [In:] Advances in Organ Biology, M.Zaidi, [Ed.], 5a: 107-118, JAI Press Inc., London 1998.

11. A.S. French, Mechanotransduction, Ann. Rev. Physiol., 54:135-152, 1992.

12. M. Kernan, D. Cowan, and C. Zuker, Genetic dissection of mechanoreception-defective mutations, Drosophila Neuron, 12:11951206, 1994 .

13. D.J. Fraser and A.G. Macdonald, Crab hydrostatic pressure sensors, Nature, 371:383-384, 1994.

14. O.P. HAmill and D.W. MCBride JR., Mechanoreceptive membrane channels, American Scientist, 83:30-37, 1995.

15. C.M. HACKNEY and D.N.Furness, Mechanotransduction in vertebrate hair cells: structure and function of the stereociliary bundle, American Journal of Physiology, 268 (Cell Physiology 37) : C1-C13, 1995. 
16. C. Cui, D.O. Smith, and J. Adler, Characterization of mechanosensitive channels in Eschericia coli cytoplasmic cell membrane by wholecell patch clamp recording, Journal Membrane Biology, 144:31-42, 1995.

17. D.C.Wildron, J.F. Thain ET AL., Electrical signaling and systematic proteinase inhibitor induction in the wounded plant, Natur, 360:62-65, 1992.

18. P.Goldsmith, Plant stems: A possible model system for the transduction of mechanical information in bone modeling, Bone, 15:249-250, 1994.

19. S. Olsson and B.S. Hanson, Action potential-like activity found in fungal mycelia is sensitive to stimulation, Naturwissch., 82:30-31, 1995.

20. S.C. Cowin, L. Moss-Salentiun, and M.L. Moss, Candidates for the mechanosensory system in bone, J. Biomechanical Engineering, 113 : 191-197, 1991 .

21. M.L. Moss, Bone as a connected cellular network: modeling and testing, [In:] Topics in Biomedical Engineering, pp.117-119, G. Ross, [Ed.], Pergamon Press, New York 1991a.

22. M.L. Moss, Alternate mechanisms of bone remodeling: their representation in a connected cellular network model, Annals Biomedical Engineering, 19, p.636, $1991 \mathrm{~b}$.

23. M.V.L. Bennett and D.A. Goodenough, Gap junctions, Electronic coupling and intercellular communication, Neurosci. Res. Prog. Bull., $16: 373-485,1978$.

24. S.B. Doty, Morphological evidence of gap junctions between bone cells, Calcified Tissue International, 33:509-512, 1981.

25. S.B. Doty, Cell-to-cell communication in bone tissue, [In:] The biological mechanism of tooth eruption and root resorption, p.61-69, Z. Davidovitch, [Ed.], EBSCO Media, Birmingham, Alabama, 1989.

26. D.B. Jones and D. Bingmann, How do osteoblasts respond to mechanical stimulation?, Cells Materials, 1:329-340, 1991. 
27. K. Schirrmacher, I. Schmitz et al., Characterization of gap junctions between osteoblast-like cells in culture, Calcified Tissue International, $51: 285-290,1992$.

28. S.J. Jones, C. Gray, H. Sakamaki et al., The incidence and size of gap junctions between bone cells in rat calvaria, Anatomic Embryology, $187: 343-352,1993$.

29. R. Gourdie and C. Green, The incidence and size of gap junctions between bone cells in rat calvaria, Anatomic Embryology, 187:343-352, 1993.

30. R. Civitelli, Cell-cell communication in bone, Calcified Tissue International, 56(Suppl. 1): S29-S31, 1995.

31. R. Minkoff, V.R. Rundus, S.B. Parker et Al., Gap junction proteins exhibit early and specific expression during intramembranous bone formation in the developing chick mandible, Anatomic Embryology, pp.231-241, 1994.

32. F. Lechnda, D.A. Towler, Et.Al, Gap junctional communication modulates gene expression in osteoblastic cells, Molecular Biology of the Cell, $9: 2249-2258,1998$.

33. D.B. Cowan, S.J. Lye, and B.L. Langille, Regulation of vascular connexin 43 gene expression by mechanical loads, Circ.Res., 82:786$793,1998$.

34. M.A.Beardslee, J.G. Laing, E.C. Beyer et al., Rapid turnover of connexin 43 in the adult rat heart, Circ. Res., 83:629-635, 1998.

35. D.C. Spray, Gap junction proteins; where do they live and how do they die?, Circ. Res., 83:679-681, 1998.

36. G. Rodan, Introduction to bone biology, Bone, 13: S3-S6, 1992.

37. T.A. Curtis, S.H. Ashrafi, and D.F. Weber, Canalicular communication in the cortices of human long bones, Anat. Rec., 212:336-344, 1985.

38. D. Bingmann, D. Tetsch, and J. Fritsch, Membraneigenschaften von zellen aus knochenexplantaten, Z. Zahnartzl Implantol., IV:277281, 1988a. 
39. D. Bingmann, D. Tetsch, and J. Fritsch, Membrane properties of bone cells derived from calvaria of newborn rats (tissue culture), Pfluger's Architecture, S412 : R14-15, 1988b.

40. D. Chesnoy-Marchais, and J. Fritsch, Voltage-gated sodium and calcium currents in rat osteoblasts, J. Physiology, 398:291-311, 1988.

41. R. Massass, D. Bingmann, R. Korenstein, et Al., Membrane potential of rat calvaria bone cells: dependence on temperature, J. Cell Physiology, 144: 1-11, 1990.

42. A. Rubinacci, I. Villa Et AL., Osteocyte-bone lining cell system at the origin of steady ionic current in damaged amphibian bone, Calcified Tissue International, $63: 331-339,1998$.

43. B.G. Jeansonne, F.F. Feagin et Al., Cell-to-cell communication of osteoblasts, J. Dental Research, 58: 1415-1423, 1979.

44. K. Schirrmacher, F. Brummer et Al., Dye and electric coupling between osteoblasts-like cells in culture, Calcified Tissue International, $53: 53-60,1993$.

45. D.C. SPRAY, Physiological and pharmacological regulation of gap junction channels, pp.195-215. [In:] Molecular Mechanisms of Epithelial Cell Junctions: From Development to Disease, S. Chi, [Ed.], RG Landes, Austin, Texas 1994.

46. A.P. Moreno, M.B. Rook, ET AL., Gap junction channels: distinct voltage-sensitive and-insensitive conductance states, Biophys Journal, $67: 113-119,1994$.

47. R. NowAK, Cells that fire together, wire together, J. NIH Research, 4:60-64, 1992.

48. T.J. MARTin and K.W. NG, Mechanisms by which cells of the osteoblastic lineage control osteoclast formation and activity, J. Cellular Biochemistry, 56: 357-366, 1994.

49. I. OWAn, D.B. Burr, ET.AL., Mechanotransduction in bone:osteoblasts are more responsive to fluid forces than mechanical strain, American Physiological Society, 273 : C810-15, 1997. 
50. S.C. Cowin and D.M. Hegedus, Bone remodeling I: A theory of adaptive elasticity, J. Elasticity, 6:313-325, 1976.

51. D.P. Fyhrie and D.R. CARTER, A unifying principle relating stress to trabecular bone morphology, J. Orthopedic Research, 4:304-317, 1986.

52. R. Huiskes, H.J. Weinans, H.J. Grootenboer et al., Adaptive bone remodeling theory applied to prosthetic-design analysis, J. Biomechanics, $20: 1135-1150,1987$.

53. J. Hert, M. Liskova, and B. Landgrot, Influence of the long-term continuous bending on the bone. An experimental study on the tibia of the rabbit Folia, Morphologia, 17:389-399, 1969.

54. J. Hert, M. Liskova, and J. LAnda, Reaction of bone to mechanical stimuli. Part I. Continuous and intermittent loading of tibia in rabbit, Folia Morphologia, 19:290-300, 1971.

55. J. Hert, E. Pribylova, and M. Liskova, Reaction of bone to mechanical stimuli. Part 3. Microstructure of compact bone of rabbit tibia after intermittent loading, Acta Anatomica, 82:218-230, 1972.

56. J.A. O'Connor, L.E. Lanyon, and H. MACFie, The influence of strain rate on adaptive bone remodeling, J. Biomechanics, 15:767-781, 1982.

57. L.E. LANYON, Functional strain as a determinant for bone remodeling, Calcified Tissue International, 36 : S56-S61, 1984.

58. S.A. Goldstein, L.S. Matthews, J.L. Kuhn, et Al., Trabecular bone remodeling: an experimental model, J. Biomechanics, 24(Suppl. 1) : 135-150, 1991.

59. S.P. Fritton, K.J. McLeod, and C.T. Rubin, Quantifying the Strain History of Bone: Spatial Uniformity and Self-similarity of Low Magnitude Strains, J. Biomechanics, 33:317-325, 2000.

60. D.R. CARTER and W.C. HAYES, Bone compressive strength: the influence of density and strain rate, Science, 194:174-1175, 1976.

61. R.B. MArTin and D.B. Burr, A hypothetical mechanism for the stimulation of osteonal remodeling by fatigue damage, J. Biomechanics, $15: 137-139,1982$. 
62. T.D. Brown, D.R. Pedersen, M.L. Gray, et Al., Toward an identification of mechanical parameters initiating periosteal remodeling: a combined experimental and analytic approach, J. Biomechanics, $23: 893-905,1990$.

63. S.C. Cowin, On mechanosensation in bone under microgravity, Bone, $22: 119 \mathrm{~S}-125 \mathrm{~S}, 1998$.

64. S. Weinbaum, S.C. Cowin, and Y. Zeng, A model for the fluid shear stress excitation of membrane ion channels in osteocytic processes due to bone strain, [In:] Advances in Bioengineering, pp.317-320, (R. Vanderby Jr., Ed.), American Society of Mechanical Engineers, New York 1991.

65. S. Weinbaum, S.C. Cowin, and Y. Zeng, Excitation of osteocytes by mechanical loading-induced bone fluid shear stresses, J. Biomechanics, $27: 339-360,1994$.

66. S.C. Cowin, S. Weinbaum, and Yu Zeng, A case for bone canaliculi as the anatomical site of strain generated potentials, J. Biomechanics, $28: 1281-1296,1995$.

67. L. You, S.C. Cowin, M. Schaffler, and S. Weinbaum, A model for strain amplification in the actin cytoskeleton of osteocytes due to fluid drag on pericellular matrix, J. Biomechanics, 34 : 1375-1386, 2001.

68. T.S. Gross, J.L. Edwards, ET AL., Strain gradients correlate with sites of periosteal bone formation, J. Bone Mineral Research, 12:982988, 1997.

69. J. Klein-Nulend, A. Van der Plas, C.M. Semeins, N. E. Ajubi, J.A. Frangos, P.J. Nijweide, and E.H. Burger, Sensitivity of osteocytes to biomechanical stress in vitro, FASEB J. 9:441-445, 1995a.

70. J. Klein-Nulend, C.M. Semeins, N.E. Auubi, P. J. Nijweide, and E. H. Burger, Pulsating fluid flow increases nitric oxide (NO) synthesis by osteocytes but not periosteal fibroblasts - correlation with prostaglandin upregulation, Biochem. Biophys. Res. Commun. $217: 640-648,1995$ b.

71. K.M. Reich, C.V. Gay, and J.A. Frangos, Fluid shear stress as a mediator of osteoblast cyclic adenosine monophosphate production, J. Cellular Physiology, 143:100-104, 1990. 
72. J.L. Williams, J.P. Iannotti, A. Ham, J. Bleuit, and J.H. Chen, Effects of fluid shear stress on bone cells, Biorheology, 31:163-170, 1994.

73. C.T. Hung, S.R. Pollack, T.M. Reilly, and C.T. Brighton, Real-time calcium response of cultured bone cells to fluid flow, Clin. Orthop. Rel. Res. 313:256-269, 1995.

74. A.A. Pitsillides, S.C.F. Rawlinson, Et.Al., Mechanical straininduced NO production by bone cells: a possible role in adaptive bone (re)modeling?, FASEB J., 9: 1614-1622, 1995.

75. M. Hecker, A. Mülsch, E. Bassenge, and R. Busse, Vasoconstriction and increased flow: two principal mechanisms of shear stressdependent endothelail autocoid release, Am. J. Physiology, 265(Heart Cir. Physiol. 34) : H828-H833, 1993.

76. A. Kamiya, R. Bukhari, and T. Togawa, Adaptive regulation of wall shear stress optimizing vascular tree function, Bull. Math. Biol., $46: 127-137,1984$.

77. M.L. Moss, The primacy of functional matrices in orofacial growth, Transactions of the British Society for the Study of Orthodontic Dental Practice, 19:65-73, 1968.

78. M.L. Moss, A theoretical analysis of the functional matrix, Acta Biotheoret., $18: 195-202,1969$.

79. M.L. Moss, The muscle-bone interface: an analysis of a morphological boundary, Center for Human Growth and Development, Ann Arbor, Michigan, 1978.

80. T.A. Mcmahon, Muscles, Reflexes, and Locomotion, Princeton University Press, Princeton, New Jersey 1984.

81. K.J. MCLEOD and C.T. RUBin, The effect of low-frequency electrical fields on osteogenesis, J. Bone Joint Surgery, 74A : 920-929, 1992.

82. A.A. Rodrequez, J.C. Agre, et Al., Acoustic myography compared to electromyography during isometric fatigue and recovery, Muscle and Nerve, 16:188-192, 1993. 
83. C.T. Rubin, H.J. Donahue et al., Optimization of electric field parameters for the control of bone remodeling: exploitation of an indigenous mechanism for the prevention of osteopenia, J. Bone Mineral Research, 8(Suppl.2) : S573-S581, 1993.

84. C.T. Rubin and L.E. LANYON, Regulation of bone formation by applied dynamic loads, J. Bone Joint Surgery, 66 A : 397-415, 1984.

85. E.H. Burger and J. Klein-Nulend, Mechanotransduction in bonerole of the lacuno-canalicular network, FASEB J., 13:S101-S112, 1999.

86. E.H. Burger and J.P. Veldhuijzen, Influence of mechanical factors on bone formation, resorption, and growth in vitro, [In:] Bone, B. L/Hall [Ed.], 7:37-56, CRC Press, Boca Raton, Florida, 1993.

87. L.C. Almekinders, A.J. Banes, and C.A. Ballenger, Effects of repetitive motion on human fibroblasts, Med. Sci. Sports. Exer., 25 : 603607, 1993.

88. F. Guilak, A. Ratcliffe, and V.C. Mow, Chondrocyte deformation and local tissue strain in articular cartilage: a confocal microscopy study, J. Orthopedic Research, 13:410-421, 1995.

89. Y.M.H.F. Sauren, R.H.P. Mieremet, C.G. Groot, and J.P. SCHERFT, An electron microscopic study on the presence of proteoglycans on the mineralized matrix of rat and human compact lamellar bone, Anatomical Record, $232: 36-44,1992$.

90. E.M. Aarden, A.M. Wassenaar, M.J. Alblas, and P. J. NiJWEIDE, Immunocytochemical demonstration of extracellular matrix proteins in isolated osteocytes, Histochemical Cell Biology, 106:495501, 1996.

91. F. Shapiro, C. Cahill, et Al., Transmission electron microscopic demonstration of vimentin in rat osteoblast and osteocytic cell bodies and processes using the immunoglod technique, Anat. Rec., 241:39-48, 1995.

92. K. Piekarski, M. Munro, Transport mechanism operating between blood supply and osteocytes in long bones, Nature, 269(5623):80-82, 1977 . 
93. S.C. Cowin, Bone Poroelasticity, J. Biomechanics, 32:218-238, 1999.

94. M.L. Knothe Tate and U. Knothe, An ex vivo model to study transport processes and fluid flow in loaded bone, J. Biomechanics, 33 : 247 $254,2000$.

95. F. WASSERMAn and J.A. YAEGER, Fine structure of the osteocyte capsule and of the wall of the lacunae in bone, Zeit. für Zellforschung, $67: 636-652,1965$.

96. E.M. Aarden, E.H. Burger, and P.J. Nijweide, Function of osteocytes in bone, J. Cell Biochemistry, 55 : 287-299, 1994.

97. R.R. Cooper, J.W. Milgram, R.A. Robinson, and B. Maryland, Morphology of the osteon, J. Bone Joint Surgery, 48-A(7) : 1239-1271, 1966.

98. J.M. Weinger and M.E. Holtrop, An Ultrastructural study of bone cells: the occurrence of microtubules, microfilaments and tight junctions, Calcified Tissue Research, 14: 15-29, 1974.

99. G.J. King and M.E. Holtrop, Actin-like filaments in bone cells of cultured mouse calvaria as demonstrated by binding to heavy meromyosin, J. Cell Biology, 66 : 445-451, 1975.

100. M. OWAN and J.T. TRIFFITT, Extravascular albumin in bone tissue, J. Physiology, $257: 293-307,1976$.

101. J.A. Buckwalter, and L.C. Rosenberg, Electron Microscopic Studies of Cartilage proteoglycans. Direct Evidence for the variable length of the chondroitin sulfate-rich region of proteoglycan subunit core protein, J. Biological Chemistry, 257(16) : 9830-9839, 1982.

102. R.A. Salzstein, S.R. POllack, et Al., Electromechanical potentials in cortical bone - I. A continuum approach, J. Biomechanics, 20:261$270,1987$.

103. R.A. Salzstein and S.R. Pollack, Electromechanical potentials in cortical bone - II. Experimental analysis, J. Biomechanics, 20 : 271-280, 1987. 
104. G.C. ScOTT and E. KorostofF, Oscillatory and step response electromechanical phenomena in human and bovine bone, J. Biomechanics, $23: 127-143,1990$.

105. A.R. Gohel, A.R. Hand, and G.A. Gronowicz, Immunogold localization of beta 1-integrin in bone: effect of glucocorticoids and insulinlike growth factor I on integrins and osteocyte formation, J. Histochem. Cytochem., 43 : 1085-1096, 1995.

106. H. NAKAmURA, Localization of CD44, the hyaluronate receptor, on the plasma membrane of osteocytes and osteoclasts in rat tibiae, Cell Tissue Research, 280:225-233, 1995.

107. K. Tanaka-Kamioka, H. Kamioka, H. Ris, and S.S. Lim, Osteocyte shape is dependent on actin filaments and osteocyte processes are unique actin-rich projections, J. Bone Mineral Research, 13(10) : 1555-1568, 1998.

108. J.R. Glenney Jr., P. Kaulfus, P. Matsudaira, and K. Weber, F-actin binding and bundling properties of fimbrin, a major cytoskeletal protein of microvillus core filaments, J. Biol. Chem., 256:9283-9288, 1981.

109. A. Bretscher and K. WeBer, Fimbrin, a new microfilamentassociated protein present in microvilli and other cell surface structures, J. Cell Biology, 86 : 335-340, 1980.

110. B. Chailley, G. Nicolas, and M.C. Laine, Organization of actin microfilaments in the apical border of oviduct ciliated cells, Biology of the Cell, 67:81-90, 1989 .

111. E.M. AARDEn, The third cell - a study of the role of the osteocyte in bone, Thesis, Leiden, 1996.

112. L.E. LANYON, Osteocytes, strain detection, bone modeling and remodeling, Calcified Tissue International, 53(Suppl 1) : S102-S106, 1993.

113. B.B. Edin and M. TRulsson, Neural network analysis of the information content in population responses from human periodontal receptors, Science of Neural Networks, SPIE 1710:257-266, 1992. 
114. S.E. Guggino, D. Lajeunesse, J.A. Wagner et Al., Bone remodeling signaled by a dihydropyridine- and phenylalkylamine-sensitive calcium channel, Proceedings of the National Academy of Science, $8: 2957-$ 2966, 1989.

115. R. DunCAN and S. Misler, Voltage-activated and stretch activated $\mathrm{Ba}^{2+}$ conducting channels in an osteoblast-like cell line (URM 106), Fed European Biochemical Society, 251 : 17-21, 1989.

116. R.D. KEYNES, The kinetics of voltage-gated ion channels, Quarterly Review of Biophysics, $27: 339-434,1994$.

117. O.P. Hamill and D.W. McBride JR., The pharmacology of mechanogated membrane ion channels, Pharmacological Reviews, $48: 231-248,1996$.

118. C.E. Morris, Mechanosensitive ion channels, J. Membrane Biology, 113: 93-107, 1990.

119. A. Ghazi, C. Berrier, et Al., Mechanosensitive ion channels and their mode of activation, Biochimie, 80:357-62, 1998.

120. F. SAcHS, Biophysics of mechanoreception, Membrane Biochemistry, $6: 173-195,1986$.

121. H. Sackin, Mechanosensitive channels, Annual Review of Physiology, $57: 333-353,1995$.

122. L.V. Harter, K.A. Hruska, and R.L. Duncan, Human osteoblastlike cells respond to mechanical strain with increased bone matrix protein production independent of hormonal regulation, Endocrinology, $136: 528-535,1995$.

123. C.T. Rubin and L.E. LANyon, Osteoregulatory nature of mechanical stimuli: function as a determinant for adaptive bone remodeling, J. Orthopedic Research, 5:300-310, 1987.

124. J.H. Ravelsloot, R.J. van Houten, D.L. Ypey et al., Highconductance anion channels in embryonic chick osteogenic cells, J. Bone Mineral Research, 6:355-363, 1991. 
125. J. Ferrier, C. Grygorczyk, R. Grygorczyk, et al., $B a^{2}$-induced action potentials in osteoblastic cells, J. Membrane Biology, 123:255259, 1991.

126. L.Y. JAN, Y.N. JAN, Tracing the roots of ion channels, Cell ,69:715718, 1992.

127. D.E. Hughes, D.M. Salter, S. Dedhar et AL., Integrin expression in human bone, Journal Bone Mineral Research, 8:527-533, 1993.

128. H. Watanabe, K. Miake, and J. Sasaki, Immunohistochemical study of the cytoskeleton of osteoblasts in the rat calvaria, Acta Anat., $147: 14-23,1993$.

129. P.B. Green, Connecting gene and hormone action to form, pattern and organogenesis: biophysical transductions, J. Exp. Botany, 45(Special Issue) : 1775-1788, 1994.

130. A. Richardson and J.T. Parsons, Signal transduction through integrins: A central role for focal adhesion, Bioessays, 17:229-236, 1995.

131. E.A. Clark and J.S. BrugGe, Integrins and signal transduction pathways: the road taken, Science, 268:233-239, 1995.

132. G. Forgacs, Biological specificity and measurable physical properties of cell surface receptors and their possible role in signal transduction through the cytoskeleton, Biochem. Cell Biol., 73:317-326, 1995.

133. C. Dolce, A.J. Kinniburgh, and R. Dziak, Immediate early-gene induction in rat osteoblastic cells after mechanical deformation, Archs. Oral Biology, 41 : 1101-1108, 1996.

134. J.Y. ShyY, and S. Chien, Role of integrins in cellular responses to mechanical stress and adhesion, Current Opinion in Cell Biology, $9: 707-$ 713, 1997.

135. D.M. Salter, J.E. RobB, and M.O. Wright, Electrophysiological responses of human bone cells to mechanical stimulation: evidence for specific integrin function in mechanotransduction, J. Bone Mineral Research, $12: 1133-1141,1997$. 
136. M.C. Meazzini, C.D. Toma et Al., Osteoblast cytoskeletal modulation in response to mechanical strain in vitro, J. Bone Joint Surgery, $16: 170-180,1998$.

137. R.S. Carvalho, J.L. Schaffer, and L.C. Gerstenfeld, Osteoblasts induce osteopontin expression in response to attachment on fibronectin: demonstration of a common role for integrin receptors in the signal transduction processes of cell attachment and mechanical stimulation, J. Cellular Biochemistry, 70:376-390, 1998.

138. D.E. IngBer, Cellular basis of mechanotransduction, Biol. Bulletin, $194: 323-327,1998$.

139. P.A. JanmeY, The cytoskeleton and cell signaling: component localization and mechanical coupling, Physiological Review, 78:763-774, 1998.

140. V.J. UitTo, Extracellular matrix molecules and their receptors: an overview with special emphasis on periodontal tissues, Crit. Rev. Oral. Biol. Med., 2:323-354, 1991.

141. J.E. Dayhoff, S.R. Hameroff, R. Lahoz-Beltra et al., Intracellular mechanisms in neuronal learning: adaptive models, Int. Jt. Conf. Neural Networks, I73-I78, 1992.

142. J. Sadoshima, T. Takahashi et Al., Roles of mechano-sensitive ion channels, cytoskeleton and contractile activity in stretch-induced immediate-early gene expression and hypertrophy of cardiac myocytes, Proceedings of National Academy of Science, 89:9905-9909, 1992.

143. M. YAnAgishita, Function of proteoglycans in the extracellular matrix, Acta Path. Jap., 4:283-293, 1993.

144. N. Wang, J.P. Butler, and D.E. IngBer, Mechanotransduction across the cell surface and through the cytoskeleton, Science, 260:11241127, 1993.

145. C. Haskin and I. Cameron, Physiological levels of hydrostatic pressure alter morphology and organization of cytoskeletal and adhesion proteins in MG-63 osteosarcoma cells, Biochem. Cell Biol. 71:27-35, 1993. 
146. A.G. Petrov and P.N. Usherwood, Mechanosensitivity of cell membranes. Ion channels, lipid matrix and cytoskeleton, European Biophysics, $23: 1-19,1994$.

147. M. Machwate, A. Jullienne, M. Moukhtar, et Al., Temporal variation of c-fos protot-ocogene expression during osteoblasts differentiation and osteogenesis in developing rat bone, J. Cell Biochemistry, $57: 62-70,1995$.

148. M.W. Johnson, D.A. Chakkalakal, R.A. Harper et al., Fluid flow in bone, J. Biomechanics, 11:881-885, 1982.

149. R.H. KUFAHL and S. SAHA, A theoretical model for stress-generated fluid flow in the canaliculi-lacunae network in bone tissue, J. Biomechanics, $23: 171-180,1990$.

150. S.R. Pollack, N. Petrov, Et Al., An anatomical model for streaming potentials in osteons, J. Biomech., 17:627-636, 1984.

151. M.W. Otter, V.R. Palmieri, D.D. Wu et Al., A comparative analysis of streaming potentials In Vivo and In Vitro, J. Orthopaedic Research, $10: 710-719,1992$.

152. D. Zhang, S.C. Cowin, and S. Weinbaum, Electrical signal transmission and gap junction regulation in bone cell network: a cable model for an osteon, Ann. Biomedical Engineering, 25 : 357-374, 1997.

153. D. Zhang, S.C. Cowin, and S. Weinbaum, Electrical signal transmission in a bone cell network: The influence of a discrete gap junction, Ann. Biomedical Engineering, 26:644-659, 1998.

154. D. Zhang, S. Weinbaum, and S.C. Cowin, On the Calculation of Bone Pore Water Pressure due to Mechanical Loading, Int. J. Solids Structures, 35 : 4981-4997, 1998.

155. D. Zhang, S. Weinbaum, and S.C. Cowin, Estimates of the Peak Pressures in the Bone Pore Water, J. Biomechanical Engineering, $120: 697-703,1998 \mathrm{c}$.

156. L. Wang, S.P. Fritton, Et AL., Fluid pressure relaxation depends upon osteonal microstructure: modeling of an oscillatory bending experiment, J. Biomechanics, 32:663-672, 1999. 
157. R.M. Dillaman, Movement of ferritin in the 2 day-old chick femur, Anatomical Record, 209:445-453, 1984.

158. R.J. Montgomery, B.D. Sutker et AL., Interstitial fluid flow in cortical bone, Microvascular Research, 23:188-200, 1988.

159. T. TANAKA and A. Sakano, Differences in permeability of microperoxidase and horseradish peroxidase into alveolar bone of developing rats, J. Dental Research, 64:870-876, 1985.

160. N. Ayasaka, T. Kondo, and T. Goto et al., Differences in the transport systems between cementocytes and osterocytes in rats using microperoxidase as a tracer, Archs. Oral Biology, pp.363-368, 1992.

161. M.W. Otter, K.J. McLeod, C.T. Rubin, Effects of electromagnetic fields in experimental fracture repair, Clin. Orthop. Rel. Res., 355S : S90-S104, 1998.

162. C.T. Brighton, E. Okerehe, S. Pollack, et al., In vitro bone-cell response to a capacitively coupled electrical field. Role of field strength, pulse pattern and duty cycle, Clin. Orthop. Rel. Res., 285:255-262, 1992.

163. K.J. McLeod, H.J. Donahue, Et AL., Electric fields modulate bone cell function in a density-dependent manner, J. Bone Mineral Res., 8: 977-984, 1993.

164. J. Fuxe and L.F. Agnati, Volume Transmission in the Brain, Raven Press, New York 1991.

165. G. Marotti, The structure of bone tissues and the cellular control of their deposition, Ital. J. Anat. Embryol., 101:25-79, 1996.

166. N. Schaul, The fundamental neural mechanisms of electroencephalography, Electroencephalography and clinical neurophysiology 106:101107, 1998.

167. W.C. De Mello, The ways cells communicate, [in:] Cell-to-cell communication : 1-20, Plenum Press, New York, 1987.

168. T.P. Harrigan, J.J. Hamilton, Bone strain sensation via transmembrane potential changes in surface osteoblasts: loading rate and microstructural implications, J. Biomechanics, 26:183-200, 1993. 
169. P.J. Denning, Neural networks, American Scientist, 80:426-429, 1990.

170. R.L. Martino, C.A. Johnson, E.B. Suh, et Al., Parallel computing in biomedical research, Science, 265:902-907, 1994.

171. J. Dayhoff, Neural Network Architecture, van Nostrand Reinhold, New York 1990.

172. S. Grossberg, Neural Networks and Artificial Intelligence, MIT Press, Cambridge, MA 1988.

173. G.E. Hinton, J.A. Anderson, Parallel Models of Associative Memory, Lawrence Erlbaum Assoc Publ, Hillsdale, N.J 1989.

174. J.L. McClelland, D.E. Rumelhart, Parallel Distributed Processing, Psychological and Biological Models, Vol.2, M.I.T. Press, Cambridge, MA, 1987.

175. S.F. Zorntzer, J. Davis, C. LaU, An Introduction to Neural and Electronic Networks, Academic Press, San Diego 1990.

176. I. Kupfermann, Neural networks: they do not have to be complex to be complex, Behav. Brain. Sci., 15:767-768, 1992.

177. P.D. Wasserman, Neural computation. Theory and Practice, van Nostrand Reinhold, New York 1989.

178. A.M. PARFITt, Osteonal and hemi-osteonal remodeling: the spatial and temporal framework for signal traffic in adult human bone, J. Cell Biochemistry, $55: 273-286,1994$.

179. B. Fritzke, Growing cell structures-a self-organizing network for unsupervised and supervised learning, Neural Networks, Vol.7:1441-1460, 1994.

180. E. Kam, M.B. Hodgins, Communication compartments in hair follicles and their implication in differentiative control, Development, $114: 389-393,1992$.

181. R. Kodoma, G. EGUCHI, The loss of gap junctional cell-to-cell communication is coupled with dedifferentiation of retinal pigmented epithelial 
cells in the course of transdifferentiation into the lens, Int. J. Developmental Biology, 38:357-364, 1994.

182. G. Marotti, M. Ferretti, M.A. Muglia, et Al., A quantitative evaluation of osteoblast-osteocyte relationships on growing endosteal surface of rabbit tibiae, Bone, Vol.13:363-368, 1992.

183. M.L. Moss, The functional matrix hypothesis revisited. 1. The role of mechanotransduction, Am. J. Orthod. Dentofac. Orthop, 112:8-11, 1997a.

184. M.L. Moss, The functional matrix hypothesis revisited. 2. The role of an osseous connected cellular network, Am. J. Orthod. Dentofac. Orthop., 112:221-226, 1997b.

185. M.L. Moss and R. Young, A functional approach to craniology, Am. J. Physical Anthropology, 18:81-92, 1960.

186. M.L. Moss, The Functional Matrix, [in:] Vistas in Orthodontics, pp.8598, B. Kraus and R. Reidel, [Eds.], Lea and Febiger, Philadelphia, 1962.

187. M.L. Moss and L. Salentijn, The primary role of the functional matrices in facial growth, Am. J. Orthodontics, 55:566-577, 1969a.

188. M. L. Moss and L Salentijn, The capsular matrix, Am. J. Orthodontics, $56: 474-490,1969 b$.

189. M. L. Moss, The functional matrix hypothesis revisited. 3. The genomic thesis, Am. J. Orthod. Dentofac. Orthop., 112:338-42, 1997c.

190. M.L. Moss, The functional matrix hypothesis revisited. 4. The epigenetic antithesis and the resolving synthesis, Am. J. Orthod. Dentofac. Orthop., $112: 410-417,1997$ d.

191. U.S. Bhalla and R. IYENGAR, Emergent properties of networks of biological signaling pathways, Science, 283:381-383, 1999.

192. Y. Zeng, S.C. Cowin, and S. Weinbaum, A fiber matrix model for fluid flow and streaming potentials in the canaliculi of an osteon, Annals of Biomedical Engineering, $22:$ 280-292, 1994. 
193. R.S. Carvalho, J.E. Scott, D.M. Suga, et al., Stimulation of signal; transduction pathways in osteoblasts by mechanical strain potentiated by parathyroid hormone, J. Bone Miner. Res. 9: 999-1011, 1994.

194. R.V. Krstic, Die Gewebe des Menschen und der Saugetiere, Springer Verlag, Berlin 1978.

195. P.J. AtKinson and A.S. Hallsworth, The changing structure of aging human mandibular bone, Gerodontology, 2:57-66, 1983. 